\title{
Cochrane
}

Library

Cochrane Database of Systematic Reviews

\section{Rehabilitation for people with multiple sclerosis: an overview of Cochrane Reviews (Review)}

Amatya B, Khan F, Galea M

Amatya B, Khan F, Galea M.

Rehabilitation for people with multiple sclerosis: an overview of Cochrane Reviews.

Cochrane Database of Systematic Reviews 2019, Issue 1. Art. No.: CD012732.

DOI: 10.1002/14651858.CD012732.pub2.

www.cochranelibrary.com

Rehabilitation for people with multiple sclerosis: an overview of Cochrane Reviews (Review) 
TABLE OF CONTENTS

ABSTRACT 1

PLAIN LANGUAGE SUMMARY

BACKGROUND

Figure 1.

OBJECTIVES

METHODS

RESULTS

Figure 2.

Figure 3.

DISCUSSION

AUTHORS' CONCLUSIONS

ACKNOWLEDGEMENTS

REFERENCES

ADDITIONAL TABLES

APPENDICES

CONTRIBUTIONS OF AUTHORS

DECLARATIONS OF INTEREST

SOURCES OF SUPPORT

INDEX TERMS 
[Overview of Reviews]

\section{Rehabilitation for people with multiple sclerosis: an overview of Cochrane Reviews}

Bhasker Amatya ${ }^{1}$, Fary Khan ${ }^{1}$, Mary Galea ${ }^{1}$

1Department of Rehabilitation Medicine, Royal Melbourne Hospital, Royal Park Campus, Melbourne, Australia

Contact: Bhasker Amatya, Department of Rehabilitation Medicine, Royal Melbourne Hospital, Royal Park Campus, Poplar Road, Parkville, Melbourne, Victoria, 3052, Australia.Bhasker.Amatya@mh.org.au.

Editorial group: Cochrane Multiple Sclerosis and Rare Diseases of the CNS Group.

Publication status and date: New, published in Issue 1, 2019.

Citation: Amatya B, Khan F, Galea M. Rehabilitation for people with multiple sclerosis: an overview of Cochrane Reviews. Cochrane Database of Systematic Reviews 2019, Issue 1. Art. No.: CD012732. DOI: 10.1002/14651858.CD012732.pub2.

Copyright @ 2019 The Cochrane Collaboration. Published by John Wiley \& Sons, Ltd.

\section{A B S T R A C T}

\section{Background}

Multiple sclerosis (MS) is a major cause of chronic, neurological disability, with a significant long-term disability burden, often requiring comprehensive rehabilitation.

\section{Objectives}

To systematically evaluate evidence from published Cochrane Reviews of clinical trials to summarise the evidence regarding the effectiveness and safety of rehabilitation interventions for people with MS (pwMS), to improve patient outcomes, and to highlight current gaps in knowledge.

\section{Methods}

We searched the Cochrane Database of Systematic Reviews up to December 2017, to identify Cochrane Reviews that assessed the effectiveness of organised rehabilitation interventions for pwMS. Two reviewers independently assessed the quality of included reviews, using the Revised Assessment of Multiple Systematic Reviews (R-AMSTAR) tool, and the quality of the evidence for reported outcomes, using the GRADE framework.

\section{Main results}

Overall, we included 15 reviews published in the Cochrane Library, comprising 164 randomised controlled trials (RCTs) and four controlled clinical trials, with a total of 10,396 participants. The included reviews evaluated a wide range of rehabilitation interventions, including: physical activity and exercise therapy, hyperbaric oxygen therapy (HBOT), whole-body vibration, occupational therapy, cognitive and psychological interventions, nutritional and dietary supplements, vocational rehabilitation, information provision, telerehabilitation, and interventions for the management of spasticity. We assessed all reviews to be of high to moderate methodological quality, based on RAMSTAR criteria.

Moderate-quality evidence suggested that physical therapeutic modalities (exercise and physical activities) improved functional outcomes (mobility, muscular strength), reduced impairment (fatigue), and improved participation (quality of life). Moderate-quality evidence suggested that inpatient or outpatient multidisciplinary rehabilitation programmes led to longer-term gains at the levels of activity and participation, and interventions that provided information improved patient knowledge. Low-qualitty evidence suggested that neuropsychological interventions, symptom-management programmes (spasticity), whole body vibration, and telerehabilitation improved some patient outcomes. Evidence for other rehabilitation modalities was inconclusive, due to lack of robust studies. 


\section{Authors' conclusions}

The evidence suggests that regular specialist evaluation and follow-up to assess the needs of patients with all types of MS for appropriate rehabilitation interventions may be of benefit, although the certainty of evidence varies across the different types of interventions evaluated by the reviews. Structured, multidisciplinary rehabilitation programmes and physical therapy (exercise or physical activities) can improve functional outcomes (mobility, muscle strength, aerobic capacity), and quality of life. Overall, the evidence for many rehabilitation interventions should be interpreted cautiously, as the majority of included reviews did not include data from current studies. More studies, with appropriate design, which report the type and intensity of modalities and their cost-effectiveness are needed to address the current gaps in knowledge.

\section{PLAIN LANGUAGE SUMMARY}

\section{Rehabilitation for persons with multiple sclerosis}

\section{Review questions}

Do people with multiple sclerosis (MS), who participate in rehabilitation programmes, improve in their functional activities, disability, and quality of life compared with those who receive no rehabilitation treatment, placebo, or different types of interventions?

\section{Background}

MS is a complex condition, which requires comprehensive, long-term management. Rehabilitation programmes aim to improve function, well-being, and quality of life for people with MS. Currently, a wide variety of rehabilitation therapies are used to treat MS. Published literature, including Cochrane Reviews, that evaluates these interventions, has grown. To guide clinicians, this review assessed current Cochrane Reviews, and provides an overview of the effectiveness of rehabilitation therapies used to treat people with MS.

\section{Study characteristics}

We searched for all published Cochrane Reviews of MS clinical trials that evaluated the effectiveness of rehabilitation interventions compared with various control groups (no intervention or different type of intervention). We evaluated all relevant reviews, and summarised the findings.

\section{Key results and quality of evidence}

We included a total of 15 Cochrane Reviews, which included 168 clinical trials, and a total of 10,396 people with MS. These good-quality reviews evaluated a range of rehabilitation interventions, including: physical activity and exercise therapy, hyperbaric oxygen therapy, whole-body vibration, occupational therapy, cognitive and psychological interventions, nutritional and dietary supplements, vocational rehabilitation, information provision, telerehabilitation, and interventions for the management of spasticity.

The findings showed some benefits for people with MS who participated in exercise and physical activity programmes or multidisciplinary rehabilitation programmes (where the intervention is provided by a team of health professionals from different professions). They found improvements in everyday activities, function, and health-related quality of life, compared with those who were not offered rehabilitation. Evidence for other rehabilitation modalities was limited, due to lack of good-quality studies. More research is needed to determine whether various types of rehabilitation modalities are effective in reducing disability in people with MS. 


\section{B A C K G R O U N D}

\section{Description of the condition}

Multiple sclerosis (MS), an autoimmune inflammatory demyelinating disease of the central nervous system, is a major cause of chronic neurological disability in young and middle-aged adults (aged 18 to 50 years (Barten 2010)). MS affects approximately 1.3 million people worldwide, with a median estimated incidence of 2.5 per 100,000 (range 1.1 to 4 ) globally (WHO 2008). The global prevalence rate of MS is estimated to be 30 per 100,000 (range 5 to 80 ), with a female preponderance (female to male ratio of 3:1 (Trisolini 2010; WHO 2008)). MS is characterised by significant variability in presentation and prognosis, and is associated with complex disabilities, including disorders of strength, sensation, co-ordination and balance, visual, and cognitive deficits (Beer 2012; Khan 2007a; Khan 2007b). These impairments usually lead to progressive limitation of functioning in daily life and require long-term multidisciplinary management. Factors associated with worse prognosis are: older age at onset, progressive disease course, multiple onset symptoms, pyramidal or cerebellar symptoms, and a short interval between onset and first relapse (Hammond 2000).

MS has an unpredictable disease course and varied patterns of presentation, which include: 'relapsing-remitting' MS ( $80 \%$ of all MS cases), characterised by exacerbations and remissions, which may convert to a 'secondary-progressive' form of MS with progressive disability between attacks; 'primary-progressive' MS (15\% of all MS cases), where progressive disability develops from onset; and 'progressive-relapsing' MS (5\% of all MS cases), where the disease worsens gradually and subsequently results in discrete attacks (Amatya 2013; Khan 2007b).

People with MS (pwMS) can present with various combinations of functional deficits, such as physical disability (motor weakness, spasticity, sensory dysfunction, visual loss, ataxia, etc.), fatigue, pain, incontinence, cognitive deficits (memory, attention, executive dysfunctions), psychosocial, behavioural, and environmental problems. These have a multidimensional impact on a person's activity (function) and participation (Khan 2006; Khan 2007b). The International Classification of Functioning, Disability and Health (ICF) provides a global conceptual framework to categorise abilities and problems of persons with different health conditions, within a standard system (WHO 2001). It offers a common language for clinicians to describe functioning, disability, and health of an individual (WHO 2001). A simulated case example of the ICF model related to MS is given in Figure 1.

Figure 1. International Classification of Functioning, Disability and Health (ICF) model with case example for multiple sclerosis

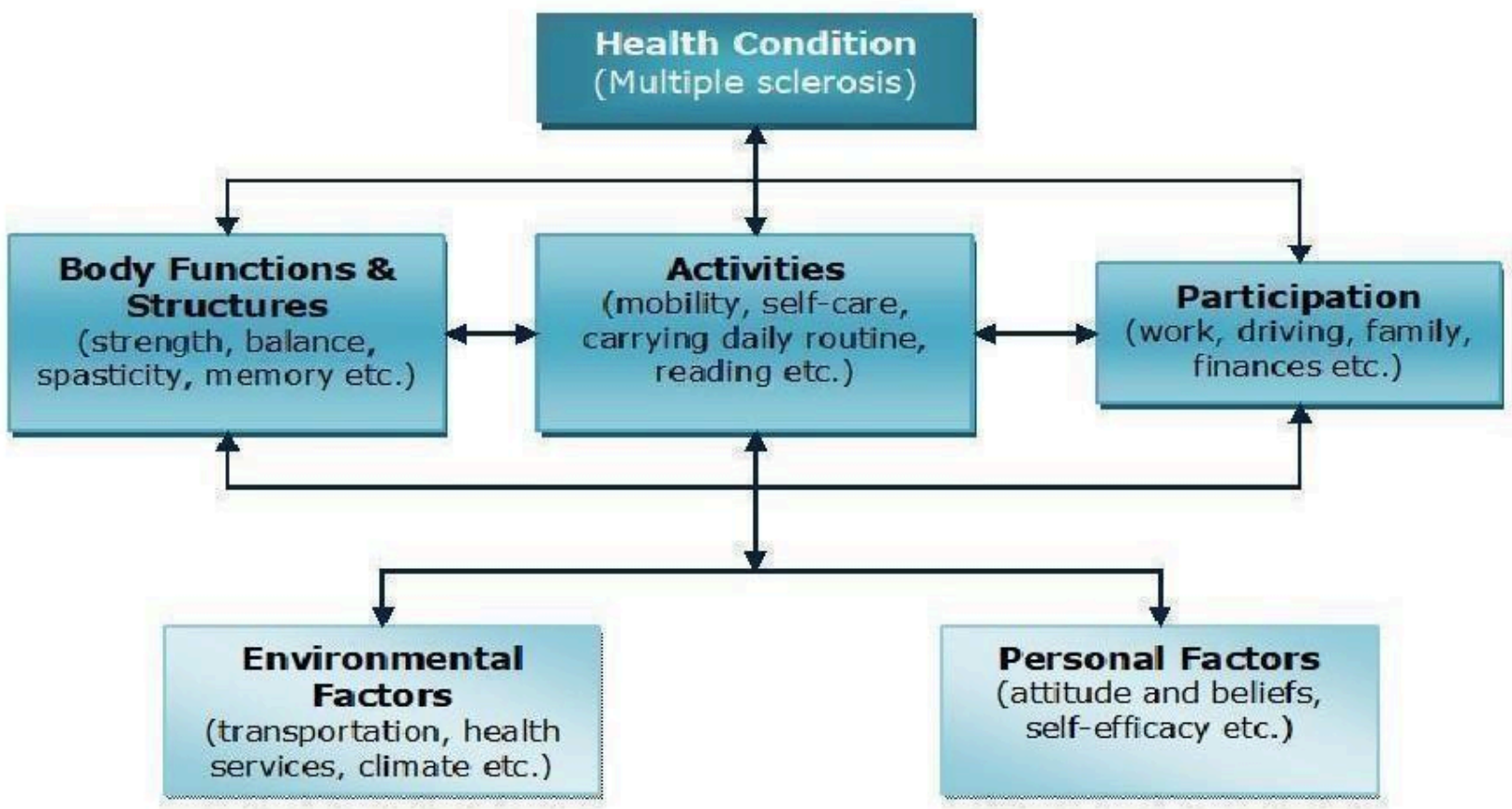

\section{Description of the interventions}

People with MS have complex care needs, due to the cumulative effects of impairments and disabilities, and the impact of ageing with disabilities, requiring comprehensive disease management, which includes rehabilitation. Medical rehabilitation is "a set of measures that assist individuals who experience (or are likely to experience) disability to achieve and maintain optimal physical, sensory, intellectual, psychological, and social functioning in interaction with their environment" (WHO 2011). It is a process of delivering a co-ordinated interdisciplinary care programme, comprising a series of therapies, which are often individualised and goal-oriented to meet the specific needs of a patient (Khan 2017). The goal of rehabilitation is to improve functional independence and enhance participation, with emphasis on patient education and self-management (Khan 2015; Beer 2012; WHO 2011). 
A comprehensive rehabilitation approach uses a range of individual or combined therapies and treatments (Khan 2007b; Khan 2010; WHO 2008). These include:

- Unidisciplinary therapy, i.e. therapy provided by a single discipline, which may include (but is not limited to): physiotherapy, occupational therapy, strengthening exercises, endurance training, resistance training, stretching, orthotics (splints, garments), casting, hyperbaric oxygen therapy (breathing pure oxygen in a specially designed pressurised room or chamber), transcutaneous electric nerve stimulation (use of electric current produced by a device to stimulate the nerves for therapeutic purposes), hippotherapy (therapy that uses the natural gait and movement of a horse to provide motor, and sensory input), vibration therapy (exercise training using vibratory platforms), vocational rehabilitation, acupuncture, psychological interventions, nutritional interventions (such as polyunsaturated fatty acids, vitamin D), mental practice, educational interventions, and specific rehabilitation programmes (such as, telerehabilitation, fatigue management, upper limb rehabilitation, and spasticity management).

- Multidisciplinary rehabilitation programmes provide a coordinated programme delivered by a specialised team of health professionals from two or more disciplines (medical, nursing, physiotherapy, occupational therapy, speech and language therapy, social work, orthotists, and others).

\section{How the intervention might work}

With advances in MS management, there has been improvement in survival rates of pwMS. Therefore, issues related to progressive disability (physical and cognitive), psychosocial adjustment, and social reintegration need to be addressed over time (Khan 2007b). In recent years, a range of rehabilitation interventions trialled in pwMS have provided increasing evidence of improved patient outcomes (Bennett 2010; Khan 2011; Khan 2017). Specifically, physical therapeutic modalities, such as physical therapy and exercise, improve muscle power and strength, exercise tolerance, and mobility-related activities (Campbell 2016; Haselkorn 2015; Heine 2015), and exercise-based programmes reduce patientreported fatigue (Andreasen 2011; Asano 2014; Heine 2015). Other potential benefits associated with physical activities include improvements in strength and muscle activity, improvement in functional capacity (including cardiorespiratory capacity), enhanced cognitive function, and haemodynamic activity (Cruickshank 2015), and neurobiological processes that could promote neuroprotection and neuroplasticity, and reduce longterm disability (White 2008a; White 2008b). These affect multiple sensorimotor processes (visual, vestibular, proprioception) to generate co-ordinated movements that maintain the centre of gravity within the limits of stability, improving balance and gait patterns (Paltamaa 2012).

There is also evidence for multidisciplinary rehabilitation for longer-term gains at the levels of activity (disability) and participation (Khan 2007b). However, other rehabilitation interventions, such as occupational therapy (Steultjens 2003), transcutaneous electrical nerve stimulation (Glinsky 2007), vibration therapy (Kantele 2015), hippotherapy (Bronson 2010), and hyperbaric oxygen therapy (Bennett 2004) have been found to have no, or limited additional benefit in pwMS (Khan 2017).

\section{Why it is important to do this overview}

MS is complex and requires a comprehensive, multidimensional approach to disease management that incorporates integrated rehabilitation interventions. The body of research for rehabilitation interventions is growing, and there are currently a number of Cochrane Reviews published on the efficacy and safety of various rehabilitation approaches. However, the published reviews vary in scope and methodology, with different, and at times diverse, conclusions about the effectiveness of the intervention evaluated. However, some review findings overlap with each other, in terms of interventions and comparisons.

Therapeutic values, including benefits and harms, associated with MS rehabilitation interventions need to be established. The most efficacious approaches, timing, and intensity of these interventions, resource requirements, and associated costs require investigation. To our knowledge, to date, no studies have comprehensively evaluated the existing Cochrane Reviews of various rehabilitation interventions in MS. Therefore, a systematic evaluation of the existing evidence from published Cochrane Reviews is required to provide the best evidence on the effectiveness of these interventions, to guide treating clinicians to achieve optimal patient outcomes. This overview can serve as a 'guiding tool' for evidence-based decisions on appropriate management approaches in pwMS, future programme improvement and design, to inform policy and healthcare decision makers, and for future research in MS.

\section{O B JECTIVES}

To systematically evaluate evidence from published Cochrane Reviews of clinical trials to summarise the evidence regarding the effectiveness and safety of rehabilitation interventions for people with multiple sclerosis (pwMS), to improve patient outcomes, and highlight current gaps in knowledge. Specific questions addressed included:

- Are rehabilitation interventions (unidisciplinary, multidisciplinary, or both) effective in minimising impairment, activity limitation, and participation restriction in pwMS?

- Are rehabilitation interventions (unidisciplinary, multidisciplinary, or both) effective in minimising the burden of care and improving quality of life in pwMS?

- What types of rehabilitation interventions (unidisciplinary, multidisciplinary, or both) are effective in pwMS, and in which setting?

\section{METHODS}

\section{Criteria for considering reviews for inclusion}

\section{Types of studies}

In accordance with the Cochrane Handbook for Systematic Reviews of Interventions, we searched the Cochrane Database of Systematic Reviews (up to December 2017) to identify Cochrane Reviews that assessed the effectiveness of organised rehabilitation interventions (unidisciplinary, multidisciplinary, or both) for pwMS (Becker 2011). We did not update the individual Cochrane Reviews. We listed all published protocols of ongoing Cochrane Reviews of rehabilitation for people with MS in the 'Classification pending references' section, for inclusion in future updates of this overview. 


\section{Types of participants}

We included all adults (18 years or over), with all subgroups of MS (relapsing-remitting, secondary-progressive, primary-progressive, and progressive-relapsing MS).

\section{Types of interventions}

We included all modalities of rehabilitation interventions in pwMS:

- unidisciplinary therapy, e.g. physiotherapy or occupational therapy only, and other interventions (as described in Description of the interventions).

- multidisciplinary rehabilitation programmes, defined as any co-ordinated therapy programme delivered by two or more disciplines (occupational therapy, physiotherapy, exercise physiology, prosthetics and orthotics, speech and language therapy, diet, and nursing care), in conjunction with medical input (neurologist or rehabilitation medicine physician) that aimed to achieve patient-centred goals (Khan 2007b).

The settings of rehabilitation programmes included:

- Ambulatory settings: outpatient or day treatment settings, which may be located within private or public hospitals, community rehabilitation centres, or specialist rehabilitation centres.

- Home-based settings (patients' own homes) and community rehabilitation settings.

- Inpatient rehabilitation settings: specialised medical rehabilitation units or hospital wards, where care is delivered 24 hours per day.

\section{Types of outcome measures}

Given the varied presentations of MS-related disability, and goals of treatment related to MS severity, we identified diverse outcomes. The list below is not conclusive, as there is a range of outcome measures that can be used to assess a particular domain. Specific outcome measures (subjective or objective) did not form part of the inclusion criteria for this review.

\section{Primary outcomes}

We categorised primary outcomes according to the International Classification of Functioning, Disability and Health (ICF (WHO 2001)). These included:

- Function (mobility, activities of daily living (ADL)): e.g. Functional Independence Measure (FIM (Granger 1990)), Timed Up And Go (TUAG (Podsiadlo 1991)), Barthel Index (BI (Mahoney 1965)), 10-metre walk test (Green 2002), or other subjective measures alone, or in combination.

- Symptoms or impairments, e.g. pain (measured by verbal scores, visual analogue scales), spasticity (using the Modified Ashworth Scale (MAS (Ansari 2009; Bohannon 1987)), and the Tardieu scale (Ansari 2008; Mehrholz 2005));

- Restriction in participation, e.g. quality of life (QoL; MS Quality of Life, MSQOL 54 (Vickrey 1997))

\section{Secondary outcomes}

These included specific outcomes that reflected:
- Measure of achievement of intended goals for treatment, e.g. goal attainment scaling or other measure of goal achievement;

- Impact on caregivers (measured with Caregiver Strain Index (CSI (Robinson 1983)));

We reported any adverse events from these interventions. For this review, we defined serious adverse events as those events that result in death, life-threatening adverse experience, inpatient hospitalisation or prolongation of existing hospitalisation (for > 24 hours), disability or permanent damage, and other important medical events (FDA 2016).

\section{Search methods for identification of reviews}

We searched the Cochrane Database of Systematic Reviews (CDSR; 2017, Issue 12 of 12) in the Cochrane Library (searched December 2017, Issue 12 of 12) for all potential reviews. We included all Cochrane Reviews registered in the CDSR that fulfilled the inclusion criteria, and reported a systematic electronic search of literature for a defined period of time. The search strategy is listed in Appendix 1. We did not apply any restriction on publication date.

\section{Data collection and analysis}

We adhered to all data collection and synthesis methodology outlined in the Cochrane Handbook for Systematic Reviews of Interventions (Becker 2011). We had no intention to repeat the assessment of eligibility, the assessment of risk of bias, or metaanalyses from the included reviews, nor to identify systematically any additional studies, or to extract additional outcomes from individual studies included in the original Cochrane Reviews (Higgins 2011).

\section{Selection of reviews}

Two review authors (BA, FK) independently screened and shortlisted all abstracts and titles of Cochrane Reviews identified by the search strategy for inclusion and appropriateness, based on the selection criteria. They independently evaluated the full text of the review to determine whether it met the inclusion and exclusion criteria. Any disagreement regarding the possible inclusion or exclusion of any review was resolved through discussion with a third review author (MG), and by a final consensus amongst all authors. We did not exclude any published Cochrane Reviews based on methodological quality.

\section{Data extraction and management}

Two review authors (BA, FK) independently extracted data from included Cochrane Reviews, using a predefined, customised electronic data extraction form. A third review author (MG) checked all extracted data for accuracy and consistency. The information obtained from the included reviews is presented in Table 1 , which comprised review objectives, publication and search date, characteristics of included studies, population characteristics, characteristics of intervention(s) covered within the scope of the review, comparison intervention(s), outcomes (primary and secondary), intervention effects, including the pooled effects, e.g. risk ratios (RRs), odds ratios (ORs), or mean differences (MDs); $95 \%$ confidence intervals (Cls), and review limitation (Higgins 2011). We extracted a narrative text of the results if no meta-analyses were performed, or statistical results were not available. We resolved any discrepancies by a final group consensus. 
We did not review the original or primary trials included in the Cochrane Reviews for additional data; we only analysed data presented in the included reviews.

We discussed all outcomes reported in the included studies of the Cochrane Reviews. We accessed the published reports of the individual trials, and had planned to contact individual researchers if any information from the reviews was unclear or missing, however, this was not required.

\section{Assessment of methodological quality of included reviews}

\section{Quality of included reviews}

Two review authors (BA, FK) independently assessed the methodological quality of each review, using the RevisedAssessment of Multiple Systematic Reviews (R-AMSTAR) appraisal tool (Kung 2010). Similar to the original AMSTAR tool (Shea 2007a; Shea 2007b), the R-AMSTAR tool contains 11 questions for assessing the methodological quality of systematic reviews (Appendix 2; Appendix 3).

We assigned a score of 1 to 4 , based on predefined criteria for each item (yes = considered adequate, or no = considered inadequate), to each domain of the R-AMSTAR tool. We used the sum of total scores, which ranged from 11 to 44 , to grade overall methodological quality. For this overview, we considered reviews that obtained scores of 40 or higher to be high quality; scores of 30 or higher to be medium quality; and scores below 29 to be low quality (Shepherd 2016). We resolved any disagreements by consensus among all review authors.

\section{Quality of included studies within reviews}

We did not assess the risk of bias of individual included studies within reviews. All of our reported study quality was according to the original Cochrane Review authors' assessments.

\section{Quality of evidence in included reviews}

We categorised all outcomes according to the ICF into: function (activity), impairment (symptoms), and participation (QoL, psychological outcomes, vocational outcomes). We used the GRADEpro GDT tool to assess quality of evidence for each type of intervention (Balshem 2011; GRADEpro GDT 2015). Two review authors (BA, FK) independently evaluated the quality of the body of evidence, based on the judgements made by the authors of the original Cochrane Reviews, such as by using the information from 'Summary of findings' tables in the included reviews, if provided. We used the GRADE system to assess the following features of the evidence of outcomes.

- Study limitations (risk of bias): internal validity of the evidence.

- Inconsistency: heterogeneity or variability in the estimates of effect across studies.

- Indirectness: degree of differences between population, intervention, comparator, for the intervention and outcome of interest.

- Imprecision (random error): extent to which confidence in the effect estimate is adequate to support a particular decision.

- Publication bias: degree of selective publication of studies.
Both review authors (BA, FK) resolved discrepancies through discussion with the third review author (MG). The quality of evidence was classified, according to Balshem 2011 as:

- High-quality: very confident that the true effect lies close to that of the estimate of the effect.

- Moderate-quality: moderately confident in the effect estimate, such that the true effect is likely to be close to the estimate of the effect, but there is a possibility that it is substantially different.

- Low-quality: confidence in the effect estimate is limited, and the true effect may be substantially different from the estimate of the effect.

- Very low-quality: very little confidence in the effect estimate, and the true effect is likely to be substantially different from the estimate of the effect.

The evidence for all relevant outcomes is summarised in a 'Summary of findings' table, along with the number of participants and studies addressing each outcomes, and the GRADE rating for each outcome. The GRADE assessments presented in the 'Summary of findings from included reviews' table are judgements made by the review authors of this overview.

\section{Data synthesis}

We compiled a narrative description of the characteristics of the included Cochrane Reviews. We considered the differences in participants, interventions, duration of follow-up, and type of data analysis in each review, along with the main findings of the effects of the interventions investigated in the included reviews, based on the GRADE system.

- Effective interventions: we found high-quality evidence of effectiveness for an intervention.

- Promising interventions (more evidence needed): we found moderate-quality evidence of effectiveness for an intervention, but more evidence is needed.

- Ineffective interventions: we found high-quality evidence of lack of effectiveness for an intervention.

- Probably ineffective interventions (more evidence needed): we found moderate-quality evidence suggesting lack of effectiveness for an intervention, but more evidence is needed.

- No conclusions possible: we found low- or very lowquality evidence, or insufficient evidence to comment on the effectiveness of an intervention.

We provided a summary of the results and statistical analysis reported in each included review in summary tables and figures, where possible. As anticipated, we found more than one eligible review of some interventions, such as physical therapy. We reported the common conclusion if these reviews had similar conclusions, and where the conclusions differed, we explored the reasons for any difference in relation to the AMSTAR scores, differences in participants, interventions, duration of follow-up, and type of data analyses in the included reviews. Further, we anticipated some overlap in the trials included among the reviews evaluating similar interventions. In such cases, we compared the results from all reviews and collated the findings, where possible. 


\section{RESULTS}

The search retrieved 85 published reviews evaluating different interventions currently used in the management of multiple sclerosis (MS). Of these, the majority $(N=64)$ evaluated pharmacological interventions, and we excluded them. Twentyone reviews met the abstract inclusion criteria, and we selected them for closer scrutiny. We retrieved the full texts of these reviews, and all review authors performed the final selection. Of these, we excluded two reviews: one review did not provide specific targeted rehabilitation intervention (Mills 2007), and another did not provide any data for the MS population (Regan 2014). Four reviews were still in the protocol stage (Amatya 2017; Cui 2010; Hayes 2017; Rietberg 2011). Overall, we included 15 reviews in this overview that were published in the Cochrane Database of Systematic Reviews (Amatya 2013; Bennett 2004; das Nair 2016; Farinotti 2012; Heine 2015; Jagannath 2010; Khan 2007b; Khan 2009; Khan 2015; Kopke 2014; Rietberg 2005; Rosti-Otajärvi 2014; Sitjà Rabert 2012; Steultjens 2003; Thomas 2006). We provided a flow diagram of the review selection process in Figure 2.

\section{Figure 2. Study flow diagram}

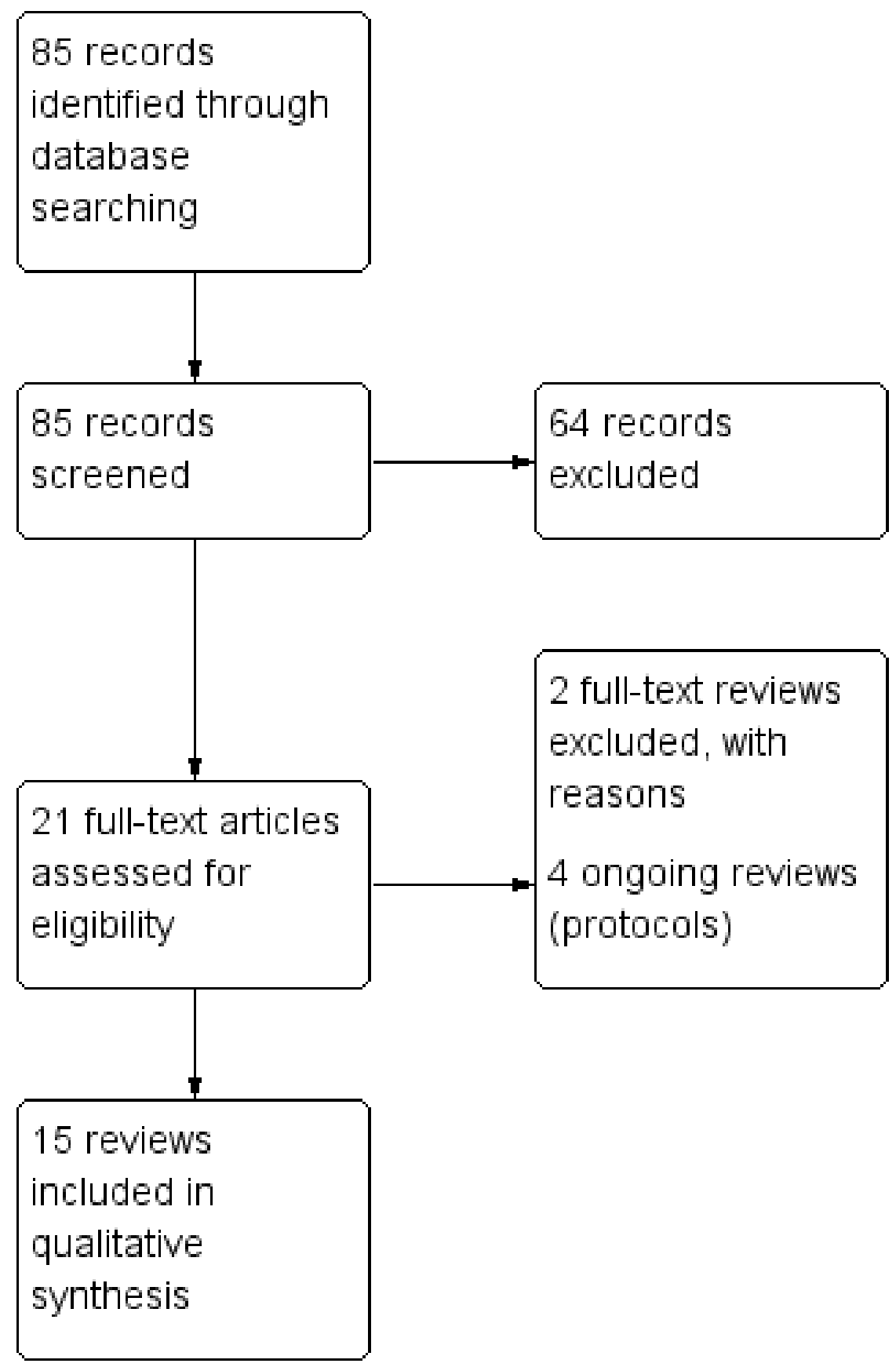




\section{Description of included reviews}

The characteristics of the 15 included Cochrane Reviews are summarised in Table 1 . The included reviews were published (or updated) between 2003 and 2016. In all reviews, searches were limited to randomised controlled trial (RCT) or clinical controlled trial (CCT) designs, and in three cases, the inclusion was limited to RCTs with follow-up of six months or longer. Overall, these 15 reviews included 164 RCTs and four CCTs, with a total of 10,396 participants.

\section{Methodological quality of included reviews}

The results of the R-AMSTAR quality assessment are provided in Appendix 2 and Appendix 3 and total scores for each included reviews are provided in Table 1 . The kappa level of agreement between the two review authors for the R-AMSTAR assessment was 0.91 . Overall, 11 included reviews were of high methodological quality (R-AMSTAR score $\geq 40$ ), and four were of moderate quality (R-AMSTAR score $=30$ to 39 (Kopke 2014; Rietberg 2005; Sitjà Rabert 2012; Steultjens 2003)). The mean R-AMSTAR methodological quality score for included reviews was 39.8 (standard deviation 2.5), and ranged from 34 to 42 , out of a possible maximum of 44 . All reviews, except one, performed a comprehensive literature search of medical science databases (Steultjens 2003), however, only half of the reviews included a grey literature search. All reviews, except two, assessed the scientific quality of the included primary studies using validated tools (Rietberg 2005; Thomas 2006). All reviews provided their funding sources, however, surprisingly, even though the reviewers declared their own conflicts of interest, none addressed the potential competing interests and source of support of authors of the primary studies. None of the reviews provided an explicit statement on the impact of findings on clinical practice guidelines.

There was heterogeneity amongst the included reviews in the tools used to assess the methodological quality of the primary studies: eight reviews used core items of the Cochrane 'Risk of bias' tool (Amatya 2013; das Nair 2016; Farinotti 2012; Jagannath 2010; Khan 2015; Kopke 2014; Rosti-Otajärvi 2014; Sitjà Rabert 2012), three used van Tulder's methodological quality checklist (Khan 2007b; Khan 2009; Steultjens 2003), one used both the PEDro checklist and the Cochrane 'Risk of bias' tool (Heine 2015), one used the Jadad score (Bennett 2004), one used a self-designed 11-point checklists (Rietberg 2005), and Thomas 2006 just used a single item; 'random allocation had been adequately concealed'. The review authors of seven included reviews used the GRADE method to rate the quality of the evidence supported by the primary trials (Amatya 2013; das Nair 2016; Heine 2015; Khan 2015; Kopke 2014; Rosti-Otajärvi 2014; Sitjà Rabert 2012).

\section{Effect of interventions}

A rehabilitation approach to people with MS (pwMS) included a range of treatments and interventions. We summarised the characteristics of included reviews in Table 1, and summarised the best-evidence syntheses for rehabilitation interventions in MS below. We summarised the findings from the included reviews for each type of intervention based on outcomes according to the International Classification of Functioning, Disability and Health (ICF; Table 2). The summary of the impact of these interventions based on specific settings are shown in Figure 3. 
Figure 3. Impact of outcomes of rehabilitation interventions based on the settings of care

\begin{tabular}{|c|c|c|c|c|c|}
\hline Intervention & $\begin{array}{l}\text { No studies, } \\
\text { participants }\end{array}$ & Inpatient & Ambulatory & $\begin{array}{l}\text { Long-term/ } \\
\text { community }\end{array}$ & GRADE \\
\hline $\begin{array}{l}\text { Multidisciplinary } \\
\text { rehabilitation }\end{array}$ & 9 RCTs, 1 CCT, 954 & & & & Moderate \\
\hline Physical therapy & 54 RCTs, 2510 & & & $\vec{\partial}$ & Moderate \\
\hline Нвот & 9 RCTs, 504 & & 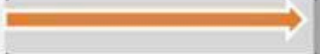 & & Low \\
\hline WBV & 4 RCTs, 64 & & $\Longrightarrow$ & & Low \\
\hline OT & 1 RCTs, 2 CCTs, 274 & & & $\Rightarrow$ & Very low \\
\hline Neuropsychological & 20 RCTs, 986 & & & $\Rightarrow$ & Low \\
\hline Cognitive rehabilitation & 16 RCTs, 1006 & & $\vec{\overrightarrow{ }}$ & & Low \\
\hline Memory rehabilitation & 15 RCTs, 989 & & $\vec{\Rightarrow}$ & & Low \\
\hline Information provision & 10 RCTs, 1314 & & 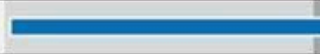 & $\Rightarrow$ & Moderate \\
\hline $\begin{array}{l}\text { Dietary intervention } \\
\text { (PUFAs) }\end{array}$ & 6 RCTs, 794 & & $\Rightarrow$ & & Low \\
\hline $\begin{array}{l}\text { Dietary intervention } \\
\text { (Vitamin D) }\end{array}$ & $1 \mathrm{RCT}, 49$ & & & & Very low \\
\hline Vocational rehabilitation & $1 \mathrm{RCT}, 1 \mathrm{CCT}, 80$ & & & $\underset{ }{\longrightarrow}$ & Low \\
\hline Telerehabilitation & 9 RCTs, 531 & & & & Low \\
\hline $\begin{array}{l}\text { Spasticity management } \\
\text { interventions }\end{array}$ & 9 RCTs, 341 & & & $\Rightarrow$ & Low \\
\hline
\end{tabular}

- Grade of Recommendation, Assessment, Development and Evaluation GRADE grades of evidence:

$\Rightarrow$ High quality Further research is very unlikely to change our confidence in the estimate of effect

Moderate quality. Further research is very likely to have an important impact on our confidence in the estimate of effect and is likely to change the

Low quality. Further research is likely to have an important impact on our confidence in the estimate of effect and may change the estimate. Very low quality. We are very uncertain about the estimate.

$\mathrm{CCT}=$ clinical controlled trial; $\mathrm{HBOT}=$ hyperbaric oxygen therapy; $\mathrm{OT}=$ occupational therapy; $\mathrm{PUFAs}=$ polyunsaturated fatty acids; $\mathrm{RCT}=$ randomised controlled trial; $\mathrm{WBV}=$ whole body vibration

We found marked heterogeneity of the evaluated interventions and measured outcomes amongst the included reviews. Various specific rehabilitation interventions evaluated in included reviews and key findings are summarized below:

\section{Multidisciplinary rehabilitation (1 review)}

Khan 2007b included 10 trials (9 RCTs and 1 CCT), with 954 participants, which evaluated various types of multidisciplinary rehabilitation in pwMS. The authors reported strong evidence for inpatient multidisciplinary rehabilitation ( 3 RCTs, $N=217$ ) in producing short-term gains at the levels of activity (disability) and participation. Strong evidence was reported for improvement in disability (total Functional Independence Measure (FIM) and Barthel Index (BI)), and level of participation (London Handicap Scale (LHS), and Human Activities Profile (HAP)). There was moderate-level evidence indicating that inpatient rehabilitation could improve symptoms (Guy's Neurological Disability Scale (GNDS)), self-care and sphincter control (FIM), and mobility and locomotion (wheelchair users only (Amended Motor Club Assessment (AMCA)).

In this review, one RCT evaluated an individualised, multidisciplinary rehabilitation programme provided in inpatient settings compared to outpatient settings ( $N=84$ participants), and reported limited evidence for short-term gains at the level of activity (ambulatory status and Incapacity Status Scale (ISS)). There was no evidence at the level of participation and reduction in the need for aids or assistance at home. The trial authors did not report details of participants and interventions, such as length of rehabilitation and contents of the rehabilitation programme. One trial, with two reports ( $\mathrm{N}=101$ participants), compared individualised (three to six weeks), multidisciplinary inpatient (three hours of intensive therapy, with blocks of sessions with physiotherapists, occupational therapists, and other allied health professionals, such as speech therapist, neuropsychologist, and social work as required), or outpatient rehabilitation (similar low intensity programme based on patient needs), with a waitinglist control group, and reported moderate evidence for reduced disability, and bladder impairment outcomes, and improved continence-related quality of life (QoL) and participation. Four RCTs evaluated the effectiveness of outpatient multidisciplinary rehabilitation versus control ( $\mathrm{N}=351$ participants), and found limited evidence for improved impairment, measured by the Expanded Disability Status Scale (EDSS), short-term benefits at the level of activity (FIM), and improved fatigue, mood, and social function. There was no convincing evidence for the costeffectiveness of any multidisciplinary programmes, or the best 'dose' of therapy (Khan 2007b). 


\section{Physical therapeutic modalities}

We identified three Cochrane Reviews that assessed physical therapeutic modalities in pwMS; findings are summarised below.

\section{Exercise (2 reviews)}

Two reviews evaluated the effectiveness of different types of exercise programmes (Heine 2015; Rietberg 2005).

Heine 2015 evaluated the effectiveness and safety of exercise therapy on fatigue in pwMS. The authors included 45 RCTs ( $N=2250$ participants), which evaluated 69 different exercise interventions: endurance training (23 interventions), muscle power training (9 interventions), task-oriented training (5 interventions), mixed training (15 interventions), or other (e.g. yoga (17 interventions)). Of these, 36 trials, with 1603 participants, provided sufficient data for the meta-analysis on fatigue. The review authors reported a significant effect on fatigue in favour of exercise therapy compared to non-exercise control (standardised mean difference (SMD) -0.53 , $95 \%$ confidence interval $(\mathrm{Cl})-0.73$ to $-0.33 ; \mathrm{P}<0.01)$. Despite the significant heterogeneity between trials $\left(I^{2}>58 \%\right)$ and the overall methodological quality, the combined body of evidence was of moderate quality. In a subgroup analysis, the authors also reported a significant effect on fatigue in favour of exercise therapy compared to no exercise for endurance training (SMD -0.43, 95\% $\mathrm{Cl}-0.69$ to $-0.17 ; \mathrm{P}<0.01$ ), mixed training (SMD $-0.73,95 \% \mathrm{Cl}-1.23$ to $-0.23 ; \mathrm{P}<0.01$ ), and other training (SMD $-0.54,95 \% \mathrm{Cl}-0.79$ to $-0.29 ; \mathrm{P}<0.01)$. Across all studies, exercise did not seem to be associated with a significant risk of a relapse of MS or adverse events. The authors concluded that exercise therapy (endurance, mixed, or other training) could reduce self-reported fatigue, and could be prescribed for pwMS without harm.

Rietberg 2005 examined the effectiveness of exercise therapy for pwMS on activities of daily living (ADL) and health-related QoL (9 RCTs, 260 participants). Six trials compared exercise therapy with no exercise therapy, while three trials compared two different types of exercise therapy interventions. There was strong evidence that exercise-based rehabilitation improved muscle power, exercise tolerance, and mobility-related activities; moderate evidence that it improved mood; but no evidence for fatigue. Exercise therapy was found to be safe, with no adverse events. The review authors reported that there was no evidence on optimal type, duration, intensity, or frequency of training sessions, due to diversity amongst included trials. The authors concluded that exercise therapy could be beneficial for pwMS who were not experiencing an exacerbation.

\section{Hyperbaric oxygen therapy (HBOT; 1 review)}

Bennett 2004 evaluated the efficacy and safety of HBOT in pwMS (9 RCTs, 504 participants). The initial treatment course of HBOT consisted of 20 treatment sessions over four weeks; the dose of oxygen per treatment session varied between studies. Two trials produced modest, positive results; however, these were isolated, and difficult to ascribe biological plausibility. There was some improvement in the mean EDSS score at 12 months in the HBOT group (group mean reduction in EDSS compared to sham -0.85 of a point, $95 \% \mathrm{Cl}-1.28$ to $-0.42 ; \mathrm{P}=0.0001$ ). Seven trials reported no evidence of a general treatment effect. There was inconsistent evidence of benefit for the secondary outcomes, such as fatigue, pyramidal system function, and sphincter function. Overall findings suggested that there was no consistent evidence to confirm a beneficial effect of HBOT in pwMS.

\section{Whole-body vibration (WBV; 1 review)}

Sitjà Rabert 2012 examined the efficacy of WBV on functional performance in persons with neurodegenerative diseases, including MS. Of 10 RCTs identified, 4 RCTs, with 64 participants, were conducted in the MS population. The included trials used different vibration parameters (range from 2 to $26 \mathrm{~Hz}$ ) and different vibration platform types (rotational platform, platform that generates vertical sinusoidal displacements, or random platform). The authors found no evidence of a short-term or longterm effect of WBV on any functional outcomes (body balance, gait, muscle performance) or QoL, compared with other active physical therapy or passive interventions.

\section{Occupational therapy (1 review)}

Steultjens 2003 evaluated the efficacy of occupational therapy (OT) on functional outcomes, and social participation, healthrelated QoL, or both, in pwMS. The authors found three trials (1 RCT and 2 CCTs, 274 participants). The OT approach evaluated a group energy conservation course ( 2 trials) and counselling intervention. The review authors found inconclusive evidence for any OT interventions in pwMS. Two included trials (both CCTs) reported a beneficial effect of energy conservation group therapy, however, the evidence was insufficient, due to methodological flaws.

\section{Cognitive and psychological interventions (3 reviews)}

Rosti-Otajärvi 2014 assessed the effects of neuropsychological, cognitive rehabilitation on cognitive performance and emotional well-being in pwMS (20 RCTs, 986 participants). The review authors reported that cognitive training improved memory span (SMD 0.54, $95 \% \mathrm{Cl} 0.20$ to $0.88 ; \mathrm{P}=0.002$ ), and working memory (SMD 0.33 , $95 \% \mathrm{Cl} 0.09$ to $0.57 ; \mathrm{P}=0.006$ ). Cognitive training combined with other neuropsychological rehabilitation methods also improved attention (SMD 0.15, 95\% $\mathrm{Cl} 0.01$ to $0.28 ; \mathrm{P}=0.03$ ), immediate verbal memory (SMD $0.31,95 \% \mathrm{Cl} 0.08$ to $0.54 ; \mathrm{P}=0.008$ ), and delayed memory (SMD $0.22,95 \% \mathrm{Cl} 0.02$ to $0.42 ; \mathrm{P}=0.03$ ). No improvement was found for emotional function. The overall quality of the included studies was low, due to methodological limitations and heterogeneity of interventions and outcome measures. The review authors concluded there was low-quality evidence suggesting that neuropsychological rehabilitation improved cognitive functions (improved memory span, working memory, attention), but none for emotional function.

Thomas 2006 evaluated the effectiveness of psychological interventions, including cognitive behavioural therapy (CBT), in pwMS (16 RCTs, 1006 participants). CBT was found to be beneficial in the treatment of depression, and in helping people adjust to, and cope with, having MS. The authors were unable to interpret results conclusively, due to the range of outcome measures used, and heterogeneity amongst the trials. Psychological interventions were diverse in nature; CBT was the most frequently used approach. None of the studies focused on psychological approaches to managing common symptoms of MS, such as fatigue and pain. The majority of the included studies had various methodological flaws, including small sample size, lack of proper randomisation and allocation concealment methods, and lacked a clear description of withdrawals. 
das Nair 2016 evaluated the effectiveness of memory rehabilitation on memory functions and functional abilities in a subgroup of pwMS with memory problems, compared to those who were given no treatment, or received a placebo. The review authors included 15 RCTs, with a total of 989 participants, which evaluated a wide range of memory retraining techniques, such as computerised programmes, and internal and external memory aids. The findings suggested a significant effect of the interventions on objective assessments of memory at both the immediate- (SMD 0.23, 95\% $\mathrm{Cl} 0.05$ to 0.41 ), and long-term follow-up (SMD $0.26,95 \% \mathrm{Cl} 0.03$ to 0.49 ), and on QoL in the immediate-term follow-up (SMD 0.23 , $95 \% \mathrm{Cl} 0.05$ to 0.41 ). The intervention group performed significantly better than the control group in ADLs at long-term follow-up (SMD $-0.33,95 \% \mathrm{Cl}-0.63$ to -0.03$)$. There was no significant effect on subjective reports of memory problems at short-term (SMD 0.04, $95 \% \mathrm{Cl}-0.19$ to 0.27 ), or long-term follow-up (SMD 0.04, $95 \% \mathrm{Cl}-0.19$ to 0.27 ); on mood at short-term (SMD $0.02,95 \% \mathrm{Cl}-0.16$ to 0.20 ), or long-term follow-up (SMD $-0.01,95 \% \mathrm{Cl}-0.21$ to 0.20 ); at shortterm follow-up for ADL (SMD $-0.13,95 \% \mathrm{Cl}-0.60$ to 0.33 ); or at longterm follow-up for QoL (SMD $0.16,95 \% \mathrm{Cl}-0.03$ to 0.36 ). The authors concluded that there was low-quality evidence suggesting that memory rehabilitation techniques may improve memory function and QoL.

\section{Nutritional and dietary supplement intervention ( 2 reviews)}

Farinotti 2012 evaluated the efficacy and safety of dietary regimens for pwMS (6 RCTs, 794 participants). These studies evaluated different form of polyunsaturated fatty acids, given for 12 to 30 months, including omega- 6 fatty acids (N-6 PUFA) - linoleic acid, or omega-3 fatty acids (N-3 PUFA) - fish oil. The review authors reported that polyunsaturated fatty acids did not have significant effects on clinical outcomes in MS (disease progression). Similarly, they found that omega- 6 fatty acids and linoleic acid had no beneficial effects. There were inconclusive data on safety.

Jagannath 2010 assessed the safety and effectiveness of vitamin $D$ in the management of MS. The authors found only one RCT conducted over 52 weeks, which treated 25 patients with escalating doses of vitamin $\mathrm{D}$ compared with controls $(\mathrm{N}=24)$. Participants in the intervention group received $40,000 \mathrm{IU} /$ day over 28 weeks to raise serum 25-hydroxyvitamin D $(25(\mathrm{OH}) \mathrm{D})$ rapidly, followed by $10,000 \mathrm{IU} /$ day for 12 weeks; they were then down-titrated to 0 IU/day. The control group received a regular dose (4000 IU/day) of vitamin D. There was limited evidence that escalating doses of vitamin D might improve relapse rates, disability scores, and suppression of T-cell proliferation. Vitamin D was safe, with no adverse effects. However, the study was of low quality, with a potential high risk of bias, which limited the generalisability of the findings.

\section{Vocational rehabilitation (1 review)}

Khan 2009 examined the effectiveness of vocational rehabilitation programmes compared to alternative programmes or usual care on return to work, work ability, and employment in pwMS. The authors only found two poor quality trials (1 RCT and 1 CCT, 80 participants). The evidence was inconclusive for the effects of specific vocational interventions on outcomes, such as: competitive employment, altering rates of job retention, changes in employment, rates of re-entry into labour force, altering work ability, employability maturity, or job-seeking activity. The authors highlighted the need for clinicians to be aware of vocational issues, to incorporate practical solutions to deal with work disability, and workplace accommodation, and to educate employers and the wider community to understand and manage barriers for maintaining employment.

\section{Information-provision interventions (1 review)}

Kopke 2014 evaluated the effectiveness of information-provision interventions for pwMS, to promote informed choices and improve patient-relevant outcomes. The authors found 10 RCTs (1314 participants), which included interventions providing diseasespecific information, such as information leaflets, booklets, manuals or pamphlets, educational programmes or lectures, audio-visual aids, like videos, tape recordings, computer programmes or websites, web systems, including podcasts, social networks or other information technologies (smartphones, decision-support tools), or personal information (e.g. house visits or telephone calls). The authors reported moderate-quality evidence for MS-related knowledge delivery programmes ( $N=$ 4 RCTs, 524 participants) in successfully increasing participants' knowledge. There were mixed results and low-quality evidence from studies reporting effects on decision-making ( $N=4$ RCTs, 836 participants), and from studies assessing QoL ( $\mathrm{N}=5 \mathrm{RCTs}, 605$ participants). The authors concluded that providing information to pwMS seemed to increase disease-related knowledge, with less clear results on decision making and QoL.

\section{Other reviews on specific rehabilitation interventions}

\section{Telerehabilitation (1 review)}

Khan 2015 examined the effectiveness and safety of telerehabilitation intervention in pwMS (9 RCTs, 531 participants). These studies evaluated various telerehabilitation interventions with more than one rehabilitation component, and predominantly included physical activity, educational, behavioural, and symptommanagement programmes. There was low-quality evidence for any form of telerehabilitation interventions in reducing shortterm disability, impairments (such as fatigue, pain, insomnia); or in improving functional activities, psychological outcomes, or QoL in the longer term. There were no data on costeffectiveness or process evaluation (participants' and therapists' satisfaction). Despite the lack of high-quality evidence, the authors concluded that a range of telerehabilitation interventions could be an alternative efficient and cost-effective method to deliver rehabilitation treatment in a setting convenient to the patient, and in remote areas where there were limited rehabilitation services.

\section{Interventions for the management of spasticity (1 review)}

Amatya 2013 evaluated non-pharmacological interventions for treating spasticity in pwMS. The authors included 9 RCTs, with 341 participants, which evaluated a wide range of nonpharmacological interventions: physical activity programmes (such as physiotherapy, structured exercise programmes, sports climbing), transcranial magnetic stimulation (intermittent theta burst stimulation (iTBS), repetitive transcranial magnetic stimulation (rTMS)), electromagnetic therapy, transcutaneous electrical nerve stimulation (TENS); and whole body vibration. The authors reported low-quality evidence that physical activity programmes used in isolation, or in combination with other interventions (pharmacological or non-pharmacological), and for magnetic stimulation (iTBS, rTMS), with or without adjuvant exercise therapy may improve spasticity in pwMS. There was no 
evidence to support the use of TENS, sports climbing, or vibration therapy for treating spasticity in this population.

\section{DISCUSSION}

\section{Summary of main results}

This review systematically summarised the best, up-to-date evidence from published Cochrane Reviews for the effectiveness of rehabilitation interventions in people with multiple sclerosis (pwMS). Rehabilitation is considered to be a key supportive treatment in MS. A range of rehabilitative approaches have been evaluated in this population. However, findings indicate that evidence to support the use of various interventions is relatively poor. There is a lack of high-quality evidence for the effectiveness of various modalities, due to the limited number of methodologically robust studies. The key findings of this review, based on outcomes according the International Classification Functioning, Disability and Health (ICF) framework that focus on the following categories, are outlined in Table 2, and summarised below:

\section{Function}

- Moderate-quality evidence that inpatient or outpatient multidisciplinary rehabilitation programmes improved functional activities and bladder related activity.

- Moderate-quality evidence that physical therapeutic modalities (exercise, physical activities) improved functional outcomes (mobility, muscular strength).

- Low-quality evidence that exercise therapy may improve balance.

- Low-quality evidence that whole body vibration may improve any functional outcomes (balance, gait, muscle performance), or QoL.

- Low-quality evidence that telerehabilitation may reduce shortterm disability and improve functional activities.

\section{Impairments}

- Moderate-quality evidence that physical therapeutic modalities (exercise, physical activities) reduced patient-reported fatigue.

- Low-quality evidence that multidisciplinary rehabilitation (outpatient and home-based) programmes might provide shortterm improvements in symptoms.

- Low-quality evidence that specific therapy programmes targeting MS-related spasticity may improve spasticity.

- Low-quality evidence that telerehabilitation may reduce symptoms (such as fatigue, pain, insomnia).

\section{Participation}

- Moderate-quality evidence that inpatient or outpatient multidisciplinary rehabilitation programmes improved participation outcomes (such as QoL) up to 12 months.

- Moderate-quality evidence that information provision increased patient's knowledge.

- Moderate-quality evidence that exercise therapy improved psychological symptoms (such as mood) and QoL

- Low-quality evidence that neuropsychological interventions may improve memory span, working memory, and attention.
- Low-quality evidence that cognitive behavioural therapy may improve depression, adjustment, and the ability to cope with MS.

- Low-quality evidence that memory rehabilitation programmes may improve memory immediately, and in the long-term.

- Low-quality evidence that whole body vibration may improve QoL.

- Low-quality evidence that vocational rehabilitation may improve competitive employment, job retention, changes in employment, rates of re-entry into the labour force; work ability by improving participants' confidence in the accommodation request process, employability maturity, or job seeking activity.

- Low-quality evidence for telerehabilitation may improve QoL and psychological outcomes.

Synthesis of best evidence from this review, based on type of rehabilitation interventions, suggest there was:

\section{Moderate-quality evidence for:}

- Inpatient or outpatient multidisciplinary rehabilitation programmes to improve disability, bladder related activity, and participation outcomes up to 12 months.

- Physical therapeutic modalities (exercise, physical activities) to improve functional outcomes (mobility, muscular strength) and QoL, reduce patient-reported fatigue.

- Information provision to increase patient's knowledge.

- Exercise therapy to improve psychological symptoms (such as mood).

\section{Low-quality evidence for:}

- Multidisciplinary rehabilitation (outpatient and home-bases) programmes that may improve symptoms and disability in the short term.

- Exercise therapy that may improve balance and symptoms.

- Neuropsychological interventions that may improve memory span, working memory, and attention.

- Cognitive behavioural therapy that may improve depression, adjustment, and the ability to cope with MS.

- Memory rehabilitation programmes that may improve memory or functional abilities, immediately or in the long term.

- Whole body vibration that may improve any functional outcomes (balance, gait, muscle performance), or QoL.

- Specific therapy programmes targeting MS-related spasticity that may improve spasticity.

- Vocational rehabilitation that may improve competitive employment, job retention, changes in employment, rates of re-entry into the labour force; work ability by improving participants' confidence in the accommodation request process, employability maturity, or job seeking activity.

- Telerehabilitation that may reduce short-term disability, improve functional activities, impairments (such as fatigue, pain, insomnia), QoL, and psychological outcomes.

\section{Inconclusive evidence for:}

- Occupational therapy strategies on functional ability, social participation, QoL, or a combination.

- Hyperbaric oxygen therapy on any patient outcomes. 
- Neuropsychological interventions on emotional function.

- Dietary interventions (polyunsaturated fatty acids, vitamin D) on clinical outcomes.

\section{Overall completeness and applicability of evidence}

This overview of Cochrane Reviews investigating the effectiveness of rehabilitation interventions in pwMS found a large degree of variation in interventions, outcome measurement tools, control protocols, and length of follow-up. Due to this heterogeneity, we were unable to pool data in meta-analyses, and were only able to conduct best-evidence syntheses using qualitative analyses. The identified heterogeneity may also reflect the wide variety of rehabilitation interventions, conducted in different settings, under different healthcare systems, with patients with varied severity and stages of MS. This review only included published Cochrane Reviews. The authors acknowledge that the overall summary reported in this review cannot be regarded as the best and most inclusive findings, as we excluded many published, relevant non-Cochrane reviews in this area (Andreasen 2011; Asano 2014; Bilkman 2013; Bronson 2010; Campbell 2016; Cruickshank 2015; Dalgas 2015; Glinsky 2007; Haselkorn 2015; Kalron 2015; Kantele 2015; Kjolhede 2012; Latimer-Cheung 2013; Mitolo 2015; Paltamaa 2012; Snook 2009; Yu 2014; Yu 2014a). However, the non-Cochrane reviews varied in scope and methodology, and lacked a standardised reporting protocol, which resulted in diverse conclusions. Therefore, we believe that including only Cochrane Reviews in this overview, potentially provided the least biased estimate of the impact of rehabilitation interventions in pwMS. It also provided reassurance about whether or not the conclusions of individual reviews were consistent (Smith 2011).

Despite strong recommendations to update Cochrane Reviews every two years, it was more than two years since the majority of the included reviews were last published or updated. Of the 15 included reviews, only one review included evidence up to June 2015 (das Nair 2016). Four included reviews could be considered out of date, as these reviews only included evidence published prior to 2010, implying that recent trials may have been missed (Jagannath 2010; Rietberg 2005; Steultjens 2003; Thomas 2006). For the rest of the reviews, the literature search date had already exceeded two years, so technically, they would also be considered out of date.

Rehabilitation for pwMS should include a wide spectrum of treatment, and use different interventions, which need to be individualised, because of the diverse clinical presentations, varying levels of disability, and changing needs of these individuals (Khan 2010). This reflects the wide variety of rehabilitation interventions included in this review. However, we found that many of the evaluated interventions were broadly described; specifically exercise interventions (aerobic, strength, flexibility, mobility, range of motion, postural control and balance training, bicycle, ergometry, etc. (Rietberg 2005)), and psychological interventions (cognitive behavioural therapy, psychoanalytic therapy, counselling, psycho-education, computebased psychological training programmes, memory aids, etc. (das Nair 2016; Thomas 2006)). Sufficient details to enable replication of many of these interventions were lacking, and few studies demonstrated the implementation of their included interventions. Many of these interventions have yet to be included in comprehensive multidisciplinary rehabilitation programmes (Khan 2007b). Included reviews also failed to provided information on optimal settings, type, intensity, and duration of therapy, and cost-effectiveness of the rehabilitation inventions.

Rehabilitation interventions are complex and difficult to quantify, and the active ingredient in the intervention is not directly identifiable (Khan 2015). The majority of the reviews included a study population with all types of MS. The included reviews consistently remarked on the relatively small numbers of patients, with marked heterogeneity of disease type, clinical presentation, and goals for treatment in the primary trials. The majority of review authors also argued that control arms, specifically those that used 'usual care', were poorly described across the primary trials. There was also a marked heterogeneity amongst the outcome measures used, even to evaluate similar functional or psychological outcomes, and assessment time points in the primary trials. This was reflected in the challenges encountered in assimilating, or pooling the data in meta-analyses, or both. Therefore, the quality of the overall evidence for many of the rehabilitation interventions, and external validity of the findings, should be interpreted cautiously.

\section{Quality of the evidence}

We assessed that all included reviews were of high to moderate quality, however, many were not recently published or updated. The quality of the evidence supporting the findings was limited by the small number of primary studies, and methodological limitations of these trials within the included reviews. The main sources of bias in the primary studies were methodological limitations, such as inadequate or lack of blinding of participants and outcome assessors, and inadequate reporting of allocation concealment and randomisation methods. There were also inconsistencies and heterogeneity in the outcome measures, and assessment and follow-up periods. Many studies included relatively small numbers of participants (statistically underpowered), and there was a marked heterogeneity in disease types and clinical presentation of the participants, and goals for treatment. We could not rule out some degree of selection, publication, and reference bias from the literature searches in the included reviews.

\section{Potential biases in the overview process}

Overall, data from the included Cochrane Reviews did not provide clinically relevant evidence for the majority of rehabilitation interventions of interest. This might be due to several limitations in the review process. We only included currently published Cochrane Reviews. Although these reviews strictly followed the Cochrane guidelines, and adopted a thorough search strategy, many were not updated; therefore, there is a strong likelihood there were missing relevant articles published beyond the search date of the included reviews. Four included reviews were conducted by the present authors' team (Amatya 2013; Khan 2007b; Khan 2009; Khan 2015), and one author (FK) was involved in another review (Kopke 2014). Independence of assessors' judgment evaluating these reviews cannot be confirmed. However, as Cochrane sets the standards for research synthesis, and as we independently followed a strict, standard appraisal protocol for all included reviews, and resolved disagreement by consensus among all review authors, we think this might have minimal impact on the overall quality assessment process. The majority of the reviews only searched for papers published in English, hence, there was a likelihood of missing data available in other languages. 


\section{Agreements and disagreements with other studies or reviews}

Haselkorn 2015 conducted a systematic review that provided an overview of the evidence for physical rehabilitation for pwMS. In contrast to this overview review, the authors included 142 individual trials (all designs; published between 1970 and 2013), rated the evidence using American Academy of Neurology criteria, and focused specifically on individual trials of physical therapies. However, this present overview used a global approach to scrutinise the MS literature, by evaluating all published Cochrane Reviews that explored a broad range of rehabilitation modalities, and using globally-endorsed appraisal methodology (AMSTAR and GRADE).

Bennett 2010 conducted a narrative review to present evidence for a specific type of exercise to control MS symptoms and improve functional recovery, but did not provide a systematic approach to the evaluation of the evidence.

Both of these reviews varied in quality, scope, and methodology, with diverse findings.

Most recently, two authors (BA, FK) systematically evaluated the evidence from published systematic reviews of clinical trials on the effectiveness of rehabilitation to improve function and participation in pwMS (Khan 2017). This overview included both Cochrane and non-Cochrane reviews, published up to 31 January 2016. Given that Khan 2017 included all the Cochrane Reviews that we included in this overview, there is considerable overlap in the findings and conclusions. Similar to Khan 2017 and Haselkorn 2015, we found that inpatient and outpatient physical therapy, and comprehensive multidisciplinary rehabilitation, improved function and disability in pwMS. However, in contrast to the previous reviews, we found only moderate-quality evidence supporting physical therapy for pwMs. This discrepancy is likely due to the stringent methodological approach we followed for this review, and the different inclusion criteria among the reviews.

\section{AUTHORS' CONCLUSIONS}

\section{Implications for practice}

Multiple sclerosis (MS) is a complex condition, which frequently presents with multiple deficits (motor, sensory, cognitive, behavioural, and communication issues) that require tailored and co-ordinated, longer-term, multidisciplinary rehabilitative care. The evidence presented in this overview of Cochrane Reviews supports the strategy that recommends varied approaches to rehabilitation. The type and setting of the rehabilitation treatment (inpatient, community) should be individualised, based on a patient's specific needs. The evidence showed that although there was a broad range of rehabilitative treatments available to treat people with MS (pwMS), there was a critical lack of high-quality evidence showing the effectiveness of various modalities. Gaps in this knowledge could be used to set directions for future research.
The literature most commonly examined the effects of different forms of physical therapeutic modalities and neuropsychological interventions in this population. Physical therapeutic modalities (exercise or physical activities) improved functional outcomes (mobility, muscle strength, aerobic capacity) and quality of life (QoL), and reduced patient-reported fatigue. A comprehensive multidisciplinary rehabilitation approach showed longer-term gains in activity (disability) and participation. However, readers should interpret the evidence for many of the rehabilitation interventions cautiously, as the majority of the included reviews found only moderate-quality evidence, and did not include the most current studies. The evaluated rehabilitation interventions were considered safe; however, many studies did not report adverse effects.

\section{Implications for research}

People with MS require specialised, flexible services for comprehensive management. In line with escalating healthcare costs, and the increased demand for rehabilitation services for pwMS, it is important to justify the expense of rehabilitation services. This overview highlights the limitations of studies in rehabilitation settings, and the need for more methodologically robust trials to build a strong evidence base in this area. Many primary trials in the included reviews tended to be of modest sample size, used a range of outcome measures, and did not always adhere to the CONSORT guidelines (das Nair 2016; Moher 2001). This limited the true picture from these studies, making it difficult to collate data for meta-analyses, and to allow informed decisions about the fidelity of the authors' conclusions (das Nair 2016). Other specific guidance, such as the intervention description and replication (TIDieR) checklist and guide may help to improve the quality of the reporting of trials of complex rehabilitation interventions (Hoffman 2014). The patients' and caregivers' perspective should be incorporated, and associated costs or economic benefit of interventions should be further explored. Participation issues relevant to MS (social reintegration, psychosocial issues, and recreational or vocational issues) need further evaluation. There is an increasing awareness of the contribution of rehabilitation in early and long-term MS care. Further research is needed to build evidence for different components, modalities, duration of rehabilitation treatments, and for interventions that can be integrated into a comprehensive, multidisciplinary, rehabilitation programme.

\section{ACKNOWLEDGEMENTS}

We thank the Editorial Board of the Cochrane Multiple Sclerosis and Rare Diseases of the Central Nervous System Group for their support and assistance. We are grateful to Dr Louisa Ng for her assistance in protocol preparation, and $\mathrm{Dr}$ Louise Geneen and $\mathrm{Dr}$ Paola Mosconi for reviewing the protocol. This study was funded and supported by the Department of Rehabilitation Medicine, Royal Melbourne Hospital, Australia. The review team received no external funding. 


\section{RE F E R E N C E S}

\section{References to included reviews}

\section{Amatya 2013}

Amatya B, La Mantia L, Demetrios M, Khan F. Non pharmacological interventions for spasticity in multiple sclerosis. Cochrane Database of Systematic Reviews 2013, Issue 2. [DOI: 10.1002/14651858.CD009974.pub2]

\section{Bennett 2004}

Bennett MH, Heard R. Hyperbaric oxygen therapy for multiple sclerosis. Cochrane Database of Systematic Reviews 2004, Issue 1. [DOI: 10.1002/14651858.CD003057.pub2]

\section{das Nair 2016}

das Nair R, Ferguson H, Stark DL, Lincoln NB. Memory rehabilitation for people with multiple sclerosis. Cochrane Database of Systematic Reviews 2016, Issue 3. [DOI: 10.1002/14651858.CD008754.pub3]

\section{Farinotti 2012}

Farinotti M, Vacchi L, Simi S, Di Pietrantonj C, Brait L, Filippini G. Dietary interventions for multiple sclerosis. Cochrane Database of Systematic Reviews 2012, Issue 12. [DOI: 10.1002/14651858.CD004192.pub3]

\section{Heine 2015}

Heine M, van de Port I, Rietberg MB, van Wegen EE, Kwakkel G. Exercise therapy for fatigue in multiple sclerosis. Cochrane Database of Systematic Reviews 2015, Issue 9. [DOI: 10.1002/14651858.CD009956.pub2]

\section{Jagannath 2010}

Jagannath VA, Fedorowicz Z, Asokan GV, Robak EW, Whamond L. Vitamin D for the management of multiple sclerosis. Cochrane Database of Systematic Reviews 2010, Issue 12. [DOI: 10.1002/14651858.CD008422.pub2]

\section{Khan 2007b}

Khan F, Turner-Stokes L, Ng L, Kilpatrick T, Amatya B. Multidisciplinary rehabilitation for adults with multiple sclerosis. Cochrane Database of Systematic Reviews 2007, Issue 2. [DOI: 10.1002/14651858.CD006036.pub2]

\section{Khan 2009}

Khan F, Ng L, Turner-Stokes L. Effectiveness of vocational rehabilitation intervention on the return to work and employment of persons with multiple sclerosis. Cochrane Database of Systematic Reviews 2009, Issue 1. [DOI: 10.1002/14651858.CD007256.pub2]

\section{Khan 2015}

Khan F, Amatya B, Kesselring J, Galea M. Telerehabilitation for persons with multiple sclerosis. Cochrane Database of Systematic Reviews 2015, Issue 4. [DOI: 10.1002/14651858.CD010508.pub2]

\section{Kopke 2014}

Kopke S, Solari A, Khan F, Heesen C, Giordano A. Information provision for people with multiple sclerosis. Cochrane
Database of Systematic Reviews 2014, Issue 4. [DOI: 10.1002/14651858.CD008757.pub2]

\section{Rietberg 2005}

Rietberg MB, Brooks D, Uitdehaag BM, Kwakkel G. Exercise therapy for multiple sclerosis. Cochrane Database of Systematic Reviews 2005, Issue 1. [DOI: 10.1002/14651858.CD003980.pub2]

\section{Rosti-Otajärvi 2014}

Rosti-Otajärvi EM, Hämäläinen PI. Neuropsychological rehabilitation for multiple sclerosis. Cochrane Database of Systematic Reviews 2014, Issue 2. [DOI: 10.1002/14651858.CD009131.pub3]

\section{Sitjà Rabert 2012}

Sitjà Rabert M, Rigau Comas D, Fort Vanmeerhaeghe A, Santoyo Medina C, Roqué i Figuls M, Romero-Rodríguez D, et al. Wholebody vibration training for patients with neurodegenerative disease. Cochrane Database of Systematic Reviews 2012, Issue 2. [DOI: 10.1002/14651858.CD009097.pub2]

\section{Steultjens 2003}

Steultjens EM, Dekker J, Bouter LM, Cardol M, Van de Nes JC, Van den Ende $\mathrm{CH}$. Occupational therapy for multiple sclerosis. Cochrane Database of Systematic Reviews 2003, Issue 3. [DOI: 10.1002/14651858.CD003608]

\section{Thomas 2006}

Thomas PW, Thomas S, Hillier C, Galvin K, Baker R. Psychological interventions for multiple sclerosis. Cochrane Database of Systematic Reviews 2006, Issue 1. [DOI: 10.1002/14651858.CD004431.pub2]

\section{References to excluded reviews}

Mills 2007

Mills RJ, Yap L, Young CA. Treatment for ataxia in multiple sclerosis. Cochrane Database of Systematic Reviews 2007, Issue 1. [DOI: 10.1002/14651858.CD005029.pub2]

\section{Regan 2014}

Regan J, Murphy A, Chiang M, McMahon BP, Coughlan T, Walshe M. Botulinum toxin for upper oesophageal sphincter dysfunction in neurological swallowing disorders. Cochrane Database of Systematic Reviews 2014, Issue 5. [DOI: 10.1002/14651858.CD009968.pub2]

\section{Additional references}

\section{Amatya 2017}

Amatya B, Young J, Khan F. Non-pharmacological interventions for chronic pain in multiple sclerosis. Cochrane Database of Systematic Reviews 2017, Issue 3. [DOI: 10.1002/14651858.CD012622]

\section{Amatya 2017a}

Amatya B, Khan F, Ng L, Galea M. Rehabilitation for people with multiple sclerosis: an overview of Cochrane systematic reviews. 
Cochrane Database of Systematic Reviews 2017, Issue 7. [DOI: 10.1002/14651858.CD012732]

\section{Andreasen 2011}

Andreasen AK, Stenager E, Dalgas U. The effect of exercise therapy on fatigue in multiple sclerosis. Multiple Sclerosis 2011;17(9):1041-54.

\section{Ansari 2008}

Ansari NN, Naghdi S, Hasson S, Azarsa MH, Azarnia S. The Modified Tardieu Scale for the measurement of elbow flexor spasticity in adult patients with hemiplegia. Brain Injury 2008;22(13-14):1007-12.

\section{Ansari 2009}

Ansari NN, Naghdi S, Hasson S, Fakhari Z, Mashayekhi M, Herasi M. Assessing the reliability of the Modified Ashworth Scale between two physiotherapists in adult patients with hemiplegia. NeuroRehabilitation 2009;25(4):235-40.

\section{Asano 2014}

Asano M, Finlayson M. Meta-analysis of three different types of fatigue management interventions for people with multiple sclerosis: exercise, education, and medication. Multiple Sclerosis International 2014;2014:1-12.

\section{Balshem 2011}

Balshem H, Helfand M, Schünemann HJ, Oxman AD, Kunz R, Brozek J, et al. GRADE guidelines: 3. Rating the quality of evidence. Journal of Clinical Epidemiology 2011;64:401-6.

\section{Barten 2010}

Barten LJ, Allington DR, Procacci KA, Rivey MP. New approaches in the management of multiple sclerosis. Drug Design, Development and Therapy 2010;24(4):343-66.

\section{Becker 2011}

Becker LA, Oxman AD. Chapter 22: Overview of reviews. In: Higgins JP, Green S, editor(s). Cochrane Handbook for Systematic Reviews of Interventions Version 5.1.0 (updated March 2011). The Cochrane Collaboration, 2011. Available from handbook.cochrane.org.

\section{Beer 2012}

Beer S, Khan F, Kesselring J. Rehabilitation interventions in multiple sclerosis: an overview. Journal of Neurology 2012;259:1994-2008.

\section{Bennett 2010}

Bennett SE. Effective rehabilitation methods in patients with multiple sclerosis. US Neurology 2010;5(2):67-70.

\section{Bilkman 2013}

Blikman LJ, Huisstede BM, Kooijmans H, Stam HJ, Bussmann JB, van Meeteren J. Effectiveness of energy conservation treatment in reducing fatigue in multiple sclerosis: a systematic review and meta-analysis. Archives of Physical Medicine and Rehabilitation 2013;94(7):1360-76.

\section{Bohannon 1987}

Bohannon RW, Smith MB. Interrater reliability of a Modified Ashworth Scale of muscle spasticity. Physical Therapy 1987;67(2):206-7.

\section{Bronson 2010}

Bronson C, Brewerton K, Ong J, Palanca C, Sullivan SJ. Does hippotherapy improve balance in persons with multiple sclerosis: a systematic review. European Journal of Physical and Rehabilitation Medicine 2010;46(3):347-53.

\section{Campbell 2016}

Campbell E, Coulter EH, Mattison PG, Miller L, McFadyen A, Paul L. Physiotherapy rehabilitation for people with progressive multiple sclerosis: a systematic review. Archives of Physical Medicine and Rehabilitation 2016;97(1):141-51.

\section{Cruickshank 2015}

Cruickshank TM, Reyes AR, Ziman MR. A systematic review and meta-analysis of strength training in individuals with multiple sclerosis or Parkinson disease. Medicine 2015;94(4):e411.

\section{Cui 2010}

Cui Y, Zhishun L, Marchese M, Lee MS, Wang J, Niu J. Acupuncture for multiple sclerosis. Cochrane Database of Systematic Reviews 2010, Issue 1. [DOI: 10.1002/14651858.CD008210]

\section{Dalgas 2015}

Dalgas U, Stenager E, Sloth M, Stenager E. The effect of exercise on depressive symptoms in multiple sclerosis based on a metaanalysis and critical review of the literature. European Journal of Neurology 2015;22(3):443-e34.

\section{FDA 2016}

US Food, Drug Adminstration. What is a serious adverse event? 2016. www.fda.gov/safety/medwatch/howtoreport/ ucm053087.htm (accessed 29 June 2017).

\section{Glinsky 2007}

Glinsky J, Harvey L, Van Es P. Efficacy of electrical stimulation to increase muscle strength in people with neurological conditions: a systematic review. Physiotherapy Research International 2007;12(3):175-94.

\section{GRADEpro GDT 2015 [Computer program]}

McMaster University (developed by Evidence Prime). GRADEpro GDT. Version accessed 15 February 2016. Hamilton (ON): McMaster University (developed by Evidence Prime), 2015.

\section{Granger 1990}

Granger CV, Cotter AC, Hamilton BB, Fiedler RC, Hens MM. Functional assessment scales: a study of persons with multiple sclerosis. Archives of Physical Medicine and Rehabilitation 1990;71(11):870-5.

\section{Green 2002}

Green J, Forster A. Reliability of gait speed measured by a timed walking test in patients one year after stroke. Clinical Rehabilitation 2002;16:306-14. 


\section{Hammond 2000}

Hammond SR, McLeod JG, Macaskill P, English DR. Multiple sclerosis in Australia: prognostic factors. Journal of Clinical Neuroscience 2000;7:16-9.

\section{Haselkorn 2015}

Haselkorn JK, Hughes C, Rae-Grant A, Henson LJ, Bever CT, Lo AC, et al. Summary of comprehensive systematic review: rehabilitation in multiple sclerosis: report of the Guideline Development, Dissemination, and Implementation Subcommittee of the American Academy of Neurology. Neurology 2015;85(21):1896-903.

\section{Hayes 2017}

Hayes S, Kennedy C, Galvin R, Finlayson M, McGuigan C, Walsh CD, et al. Interventions for preventing falls in people with multiple sclerosis. Cochrane Database of Systematic Reviews 2017, Issue 1. [DOI: 10.1002/14651858.CD012475]

\section{Higgins 2011}

Higgins JP, Green S, editor(s). Cochrane Handbook for Systematic Reviews of Interventions Version 5.1.0 (updated March 2011). The Cochrane Collaboration, 2011. Available from handbook.cochrane.org.

\section{Hoffman 2014}

Hoffman T, Glasziou P, Boutron I, Milne R, Perera R, Moher D, et al. Better reporting of interventions: template for intervention description and replication (TIDieR) checklist and guide. BMJ 2014;348:1-12.

\section{Kalron 2015}

Kalron A, Zeilig G. Efficacy of exercise intervention programs on cognition in people suffering from multiple sclerosis, stroke and Parkinson's disease: A systematic review and meta-analysis of current evidence. NeuroRehabilitation 2015;37(2):273-89.

\section{Kantele 2015}

Kantele S, Karinkanta S, Sievanen H. Effects of long-term wholebody vibration training on mobility in patients with multiple sclerosis: a meta-analysis of randomized controlled trials. Journal of the Neurological Sciences 2015;358(1-2):31-7.

\section{Khan 2006}

Khan F, McPhail T, Brand C, Turner-Stokes L, Kilpatrick T. Multiple sclerosis: disability profile and quality of life in an Australian community cohort. Internationale Zeitschrift fur Rehabilitationsforschung. Revue Internationale de Recherches de Readaptation [International Journal of Rehabilitation Research] 2006;29(2):87-96.

\section{Khan 2007a}

Khan F, Pallant JF. Use of the International Classification of Functioning, Disability and Health (ICF) to identify preliminary comprehensive and brief core sets for multiple sclerosis. Disability and Rehabilitation 2007;29:205-13.

\section{Khan 2010}

Khan F, Pallant JF, Zhang N, Turner-Stokes L. Clinical practice improvement approach in multiple sclerosis rehabilitation: a pilot study. Internationale Zeitschrift fur
Rehabilitationsforschung. Revue Internationale de Recherches de Readaptation ]International Journal of Rehabilitation Research] 2010;33(3):238-47

\section{Khan 2011}

Khan F, Amatya B, Turner-Stokes L. Symptomatic therapy and rehabilitation in primary progressive multiple sclerosis. Neurology Research International 2011;2011:1-22.

\section{Khan 2017}

Khan F, Amatya B. Rehabilitation in multiple sclerosis: a systematic review of systematic reviews. Archives of Physical Medicine and Rehabilitation 2017;98(2):356-67.

\section{Kjolhede 2012}

Kjolhede T, Vissing K, Dalgas U. Multiple sclerosis and progressive resistance training: a systematic review. Multiple Sclerosis (Houndmills, Basingstoke, England) 2012;18(9):1215-28.

\section{Kung 2010}

Kung J, Chiappelli F, Cajulis OO, Avezova R, KossanG, Chew L, et al. From systematic reviews to clinical recommendations for evidence-based health care: validation of Revised Assessment of Multiple Systematic Reviews (R-AMSTAR) for grading of clinical relevance. Open Dentistry Journal 2010;4:84-91.

\section{Latimer-Cheung 2013}

Pearson M, Dieberg G, Smart N. Exercise as a therapy for improvement of walking ability in adults with multiple sclerosis: a meta-analysis. Archives of Physical Medicine and Rehabilitation 2015;96(7):1339-48.

\section{Mahoney 1965}

Mahoney Fl, Barthel D. Functional evaluation: the Barthel Index. Maryland State Medical Journal 1965;14:56-61.

\section{Mehrholz 2005}

Mehrholz J, Wagner K, Meissner D, Grundmann K, Zange C, Koch R, et al. Reliability of the Modified Tardieu Scale and the Modified Ashworth Scale in adult patients with severe brain injury: a comparison study. Clinical Rehabilitation 2005;19:751-9.

\section{Mitolo 2015}

Mitolo M, Venneri A, Wilkinson ID, Sharrack B. Cognitive rehabilitation in multiple sclerosis: a systematic review. Journal of Neurological Sciences 2015;354(1-2):1-9.

\section{Moher 2001}

Moher D, Schultz KF, Altman D, CONSORT Group (Consolidated Standards of Reporting Trials). The CONSORT statement: revised recommendations for improving the quality of reports of parallel-group randomized trials. JAMA 2001;285:1987-91.

\section{Paltamaa 2012}

Paltamaa J, Sjögren T, Peurala SH, Heinonen A. Effects of physiotherapy interventions on balance in multiple sclerosis: a systematic review and meta-analysis of randomized controlled trials. Journal of Rehabilitation Medicine 2012;44(10):811-23. 


\section{Podsiadlo 1991}

Podsiadlo D, Richardson S. The timed 'up and go': a test of basic functional mobility for frail elderly persons. Journal of the American Geriatrics Society 1991;39:142-8.

\section{Rietberg 2011}

Rietberg MB, Veerbeek J, van Wegen EEH, Gosselink R, Kwakkel G. Respiratory muscle training for multiple sclerosis. Cochrane Database of Systematic Reviews 2011, Issue 11. [DOI: 10.1002/14651858.CD009424]

\section{Robinson 1983}

Robinson BC. Validation of a Caregiver Strain Index (CSI). Journal of Gerontology 1983;38(3):344-8.

\section{Shea 2007a}

Shea BJ, Grimshaw JM, Wells GA, Boers M, Andersson N, Hamel C, et al. Development of AMSTAR: a measurement tool to assess the methodological quality of systematic reviews. BMC Medical Research Methodology 2007;7:1-10.

\section{Shea 2007b}

Shea BJ, Bouter LM, Peterson J, Andersson N, Ortiz Z, Ramsay T, et al. External validation of a measurement tool to assess systematic reviews (AMSTAR). PLoS One 2007;2:e1350.

\section{Shepherd 2016}

Shepherd E, Middleton P, Makrides M, McIntyre S, Badawi N, Crowther CA. Neonatal interventions for preventing cerebral palsy: an overview of Cochrane systematic reviews. Cochrane Database of Systematic Reviews 2016, Issue 10. [DOI: 10.1002/14651858.CD012409]

\section{Smith 2011}

Smith V, Devane D, Begley CM, Clarke M. Methodology in conducting a systematic review of systematic reviews of healthcare interventions. BMC Medical Research Methodology 2011;11(1):15.

\section{Snook 2009}

Snook EM, Motl RW. Effect of exercise training on walking mobility in multiple sclerosis: a meta-analysis. Neurorehabilitation and Neural Repair 2009;23(2):108-16.

\section{Trisolini 2010}

Trisolini M, Honeycutt A, Wiener J, Lesesne S. Global economic impact of multiple sclerosis. www.msif.org/wp-content/
uploads/2014/09/Global_economic_impact_of_MS.pdf (accessed 03 March 2017).

\section{Vickrey 1997}

Vickrey BG, Hays RD, Genovese BJ, Myers LW, Ellison GW. Comparison of a generic to disease-targeted health related quality-of-life measures for multiple sclerosis. Journal of Clinical Epidemiology 1997;50(5):557-69.

\section{White 2008a}

White LJ, Castellano V. Exercise and brain health - implications for multiple sclerosis: part 1 - neuronal growth factors. Sports Medicine 2008;38(2):91-100.

\section{White 2008b}

White LJ, Castellano V. Exercise and brain health - implications for multiple sclerosis: part II - immune factors and stress hormones. Sports Medicine 2008;38(3):179-86.

\section{WHO 2001}

World Health Organization (WHO). International Classification of Functioning, Disability and Health (ICF). www.who.int/ classifications/icf/en/ (accessed 27 September 2016).

\section{WHO 2008}

World Health Organization (WHO). Atlas: multiple sclerosis resources in the world. www.who.int/mental_health/neurology/ Atlas_MS_WEB.pdf (accessed 27 September 2016).

\section{WHO 2011}

World Health Organization (WHO). World Report on Disability. www.who.int/disabilities/world_report/2011/report/en/ (accessed 27 September 2016).

\section{Yu 2014}

Yu CH, Mathiowetz V. Systematic review of occupational therapy-related interventions for people with multiple sclerosis: part 1. Activity and participation. American Journal of Occupational Therapy 2014;68(1):27-32.

\section{Yu 2014a}

Yu CH, Mathiowetz V. Systematic review of occupational therapy-related interventions for people with multiple sclerosis: part 2. Impairment. American Journal of Occupational Therapy 2014;68(1):33-8. 


\begin{tabular}{|c|c|c|c|c|c|c|c|c|c|c|}
\hline \multirow{3}{*}{\multicolumn{2}{|c|}{ 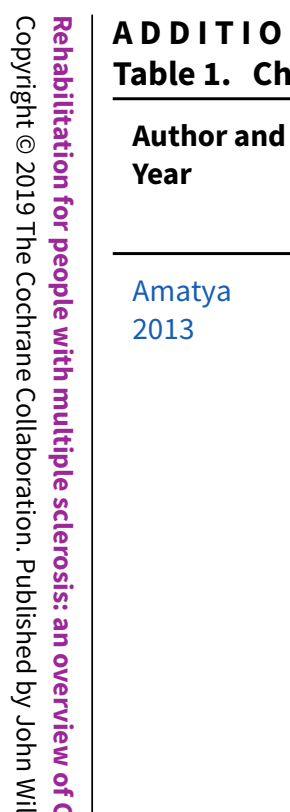 }} & \multirow[b]{2}{*}{$\begin{array}{l}\text { Date as- } \\
\text { sessed as } \\
\text { up to date }\end{array}$} & \multirow[b]{2}{*}{ Population } & \multirow[b]{2}{*}{$\begin{array}{l}\text { Interven- } \\
\text { tion }\end{array}$} & \multirow[b]{2}{*}{$\begin{array}{l}\text { Comparision } \\
\text { interventions }\end{array}$} & \multirow[b]{2}{*}{$\begin{array}{l}\text { Outcomes for which data } \\
\text { were reported }\end{array}$} & \multirow[b]{2}{*}{$\begin{array}{l}\text { Meta-analy- } \\
\text { sis }\end{array}$} & \multirow[b]{2}{*}{ Review limitations } & \multirow[b]{2}{*}{$\begin{array}{l}\text { R-AMSTR } \\
\text { score* }^{\star}\end{array}$} & \\
\hline & & & & & & & & & & 둥 \\
\hline & & $\begin{array}{l}1996 \text { to } \\
\text { June } 2012\end{array}$ & $\begin{array}{l}\mathrm{N}=9 \mathrm{RCTS} \\
341 \text { partici- } \\
\text { pants with } \\
\text { all types of } \\
\text { MS }\end{array}$ & $\begin{array}{l}\text { Non-phar- } \\
\text { macologi- } \\
\text { cal spastici- } \\
\text { ty manage- } \\
\text { ment inter- } \\
\text { ventions }\end{array}$ & $\begin{array}{l}\text { Sham or } \\
\text { placebo inter- } \\
\text { ventions; low- } \\
\text { er level or dif- } \\
\text { ferent types } \\
\text { of interven- } \\
\text { tion; minimal } \\
\text { intervention; } \\
\text { waiting-list } \\
\text { controls or no } \\
\text { treatment; in- } \\
\text { terventions } \\
\text { given in differ- } \\
\text { ent settings }\end{array}$ & $\begin{array}{l}\text { Primary } \\
\text { Reduction in spasticity; im- } \\
\text { provement in upper limb } \\
\text { functioning and (upper limb- } \\
\text { related) ADL; improvement in } \\
\text { mobility } \\
\text { Secondary } \\
\text { improvement in symptoms } \\
\text { or impairments; restriction in } \\
\text { participation and impact on } \\
\text { caregivers; costs }\end{array}$ & No & $\begin{array}{l}\text { - Results not pooled } \\
\text { sessed using graphic } \\
\text { aids and statistical tests } \\
\text { - Statement of support } \\
\text { or conflict of interest } \\
\text { in the primary inclusion } \\
\text { studies not mentioned }\end{array}$ & 41 & 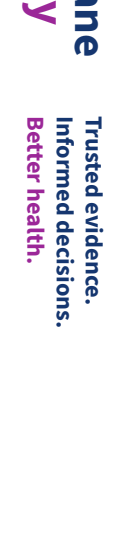 \\
\hline 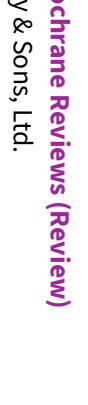 & $\begin{array}{l}\text { Bennett } \\
2004\end{array}$ & $\begin{array}{l}\text { up to } 25 \\
\text { February } \\
2011\end{array}$ & $\begin{array}{l}\text { N = } 9 \text { RCTs, } \\
504 \text { partici- } \\
\text { pants with } \\
\text { all types of } \\
\text { MS }\end{array}$ & НВОТ & $\begin{array}{l}\text { Placebo or no } \\
\text { treatment }\end{array}$ & $\begin{array}{l}\text { Primary } \\
\text { Disability status, objective as- } \\
\text { sessment; suffering } \geq 1 \text { exac- } \\
\text { erbation at } 6 \text { to } 12 \text { months; } \\
\text { side effects } \\
\text { Secondary } \\
\text { Functional scores assessed by } \\
\text { neurologists }\end{array}$ & Yes & $\begin{array}{l}\text { - Grey literature not } \\
\text { searched } \\
\text { - Non-English language } \\
\text { publication not includ- } \\
\text { ed } \\
\text { - Statement of support } \\
\text { or conflict of interest } \\
\text { in the primary inclusion } \\
\text { studies not mentioned }\end{array}$ & 41 & \\
\hline & $\begin{array}{l}\text { das Nair } \\
2016\end{array}$ & $\begin{array}{l}\text { up to June } \\
2015\end{array}$ & $\begin{array}{l}\mathrm{N}=15 \mathrm{RCTS} \\
989 \text { partici- } \\
\text { pants with } \\
\text { all types of } \\
\text { MS }\end{array}$ & $\begin{array}{l}\text { Memory re- } \\
\text { habilitation }\end{array}$ & $\begin{array}{l}\text { No treatment } \\
\text { or placebo }\end{array}$ & $\begin{array}{l}\text { Primary } \\
\text { Subjective and objective re- } \\
\text { ports of memory } \\
\text { Secondary } \\
\text { Mood, functional abilities, } \\
\text { QoL }\end{array}$ & Yes & $\begin{array}{l}\text { - Manual search of rele- } \\
\text { vant journals not con- } \\
\text { ducted } \\
\text { - Statement of support } \\
\text { or conflict of interest } \\
\text { in the primary inclusion } \\
\text { studies not mentioned }\end{array}$ & 42 & 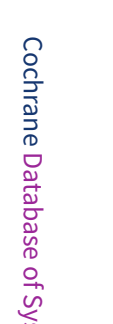 \\
\hline$\bullet$ & $\begin{array}{l}\text { Farinotti } \\
2012\end{array}$ & $\begin{array}{l}\text { up to No- } \\
\text { vember } \\
2011\end{array}$ & $\begin{array}{l}\mathrm{N}=6 \mathrm{RCTs} \\
794 \text { partici- } \\
\text { pants with }\end{array}$ & $\begin{array}{l}\text { Dietary in- } \\
\text { tervention } \\
\text { (polyunsat- } \\
\text { urated fatty }\end{array}$ & $\begin{array}{l}\text { No dietary } \\
\text { modification } \\
\text { or placebo }\end{array}$ & $\begin{array}{l}\text { Primary } \\
\text { Disability progression; exacer- } \\
\text { bation during study period }\end{array}$ & No & $\begin{array}{l}\text { - Results not pooled } \\
\text { - Grey literature and } \\
\text { manual search of rele- }\end{array}$ & 42 & 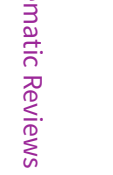 \\
\hline
\end{tabular}




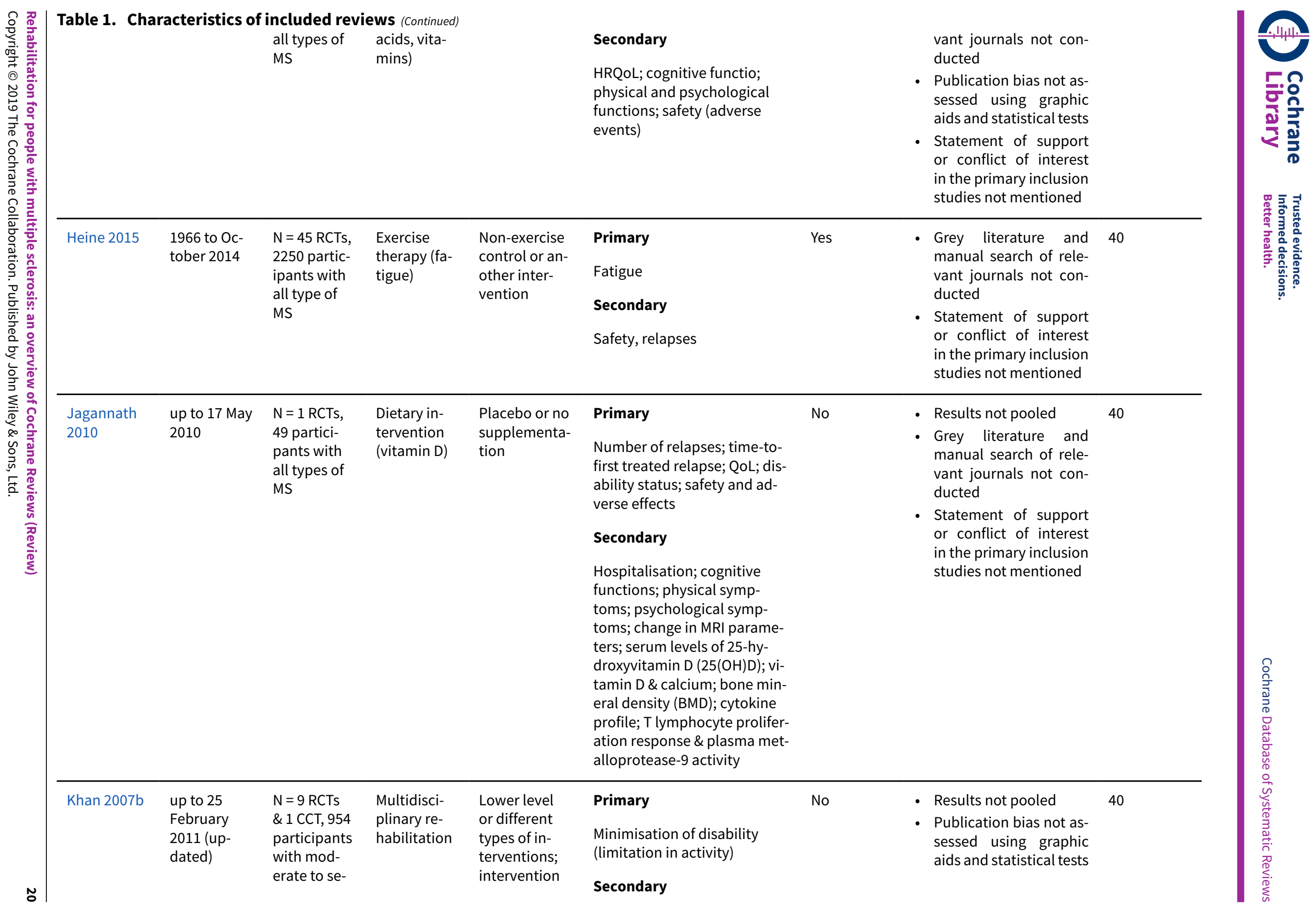




\begin{tabular}{|c|c|c|c|c|c|c|c|c|c|c|}
\hline \multirow{2}{*}{\multicolumn{2}{|c|}{ 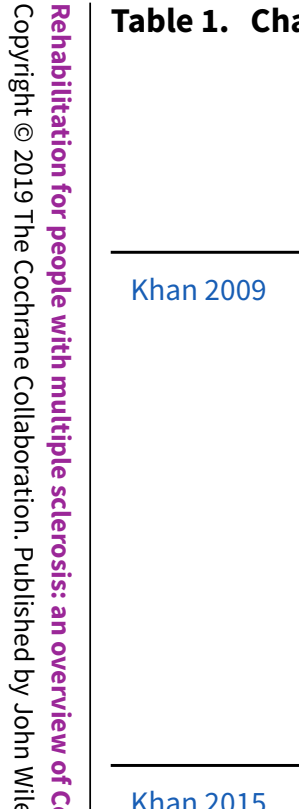 }} & \multirow[b]{2}{*}{$\begin{array}{l}1981 \text { to Feb- } \\
\text { ruary } 2011\end{array}$} & \multicolumn{2}{|c|}{$\begin{array}{l}\text { vere disabil- } \\
\text { ities }\end{array}$} & \multirow{2}{*}{$\begin{array}{l}\text { given in differ- } \\
\text { ent settings; } \\
\text { lower intensi- } \\
\text { ty of interven- } \\
\text { tion } \\
\begin{array}{l}\text { Alternative } \\
\text { programmes } \\
\text { or care as usu- } \\
\text { al }\end{array}\end{array}$} & \multicolumn{2}{|l|}{$\begin{array}{l}\text { Participatory issues, such as } \\
\text { QoL, psychological adjust- } \\
\text { ment; cost; service utilisation; } \\
\text { and care burden }\end{array}$} & \multicolumn{2}{|l|}{$\begin{array}{l}\text { - statement of support or } \\
\text { conflict of interest in } \\
\text { the primary inclusion } \\
\text { studies not mentioned }\end{array}$} & 둥ํำ \\
\hline & & & $\begin{array}{l}\mathrm{N}=1 \mathrm{RCT} \& \\
1 \mathrm{CCT}, 80 \mathrm{MS} \\
\text { participants } \\
\text { of working } \\
\text { age (mean } \\
\text { age } 18 \text { to } 65 \\
\text { years) }\end{array}$ & $\begin{array}{l}\text { Vocational } \\
\text { rehabilita- } \\
\text { tion }\end{array}$ & & $\begin{array}{l}\text { Primary } \\
\text { Competitive employment; } \\
\text { supported employment } \\
\text { Secondary } \\
\text { Return to work; disability } \\
\text { pension; work ability; costs }\end{array}$ & No & $\begin{array}{l}\text { - Results not pooled } \\
\text { - Grey literature and } \\
\text { manual search of rele- } \\
\text { vant journals not con- } \\
\text { ducted } \\
\text { - Publication bias not as- } \\
\text { sessed using graphic } \\
\text { aids and statistical tests } \\
\text { - Statement of support } \\
\text { or conflict of interest } \\
\text { in the primary inclusion } \\
\text { studies not mentioned }\end{array}$ & 40 & 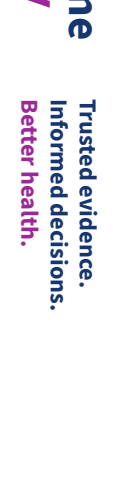 \\
\hline 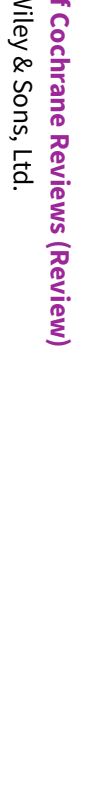 & Khan 2015 & $\begin{array}{l}\text { up to } 9 \text { July } \\
2014\end{array}$ & $\begin{array}{l}\mathrm{N}=9 \mathrm{RCTs} \\
531 \text { partici- } \\
\text { pants, (469 } \\
\text { included in } \\
\text { analyses); } \\
\text { majority } \\
\text { RRMS }\end{array}$ & $\begin{array}{l}\text { Telerehabili- } \\
\text { tation }\end{array}$ & $\begin{array}{l}\text { Lower level } \\
\text { or different } \\
\text { types of in- } \\
\text { tervention; } \\
\text { minimal in- } \\
\text { tervention; } \\
\text { waiting-list } \\
\text { controls or no } \\
\text { treatment (or } \\
\text { usual care); } \\
\text { interventions } \\
\text { given in differ- } \\
\text { ent settings }\end{array}$ & $\begin{array}{l}\text { Primary } \\
\text { Improvement in functional } \\
\text { activity (ADLs, mobility, con- } \\
\text { tinence, etc.); symptoms or } \\
\text { impairments (pain, spasm fre- } \\
\text { quency, joint range of move- } \\
\text { ment, involuntary move- } \\
\text { ments, spasticity, etc.); par- } \\
\text { ticipation and environmen- } \\
\text { tal, personal context, or both } \\
\text { (QoL, psychosocial function, } \\
\text { employment, education, so- } \\
\text { cial and vocational activities, } \\
\text { patient and caregiver mood, } \\
\text { relationships, social integra- } \\
\text { tion, etc.) } \\
\text { Secondary } \\
\text { Compliance; service utilisa- } \\
\text { tion and cost; adverse events }\end{array}$ & No & $\begin{array}{l}\text { - Results not pooled } \\
\text { - Publication bias not as- } \\
\text { sessed using graphic } \\
\text { aids } \\
\text { - Statement of support } \\
\text { or conflict of interest } \\
\text { in the primary inclusion } \\
\text { studies not mentioned }\end{array}$ & 42 & 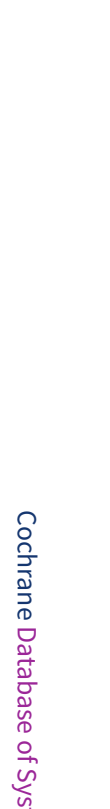 \\
\hline$N$ & Kopke 2014 & $\begin{array}{l}\text { up to } 12 \\
\text { June } 2013\end{array}$ & $\begin{array}{l}N=10 \text { RCTs, } \\
1314 \text { partic- } \\
\text { ipants with }\end{array}$ & $\begin{array}{l}\text { Information } \\
\text { provision } \\
\text { that aims }\end{array}$ & $\begin{array}{l}\text { Usual care or } \\
\text { other types } \\
\text { of informa- }\end{array}$ & Primary & No & - Results not pooled & 38 & 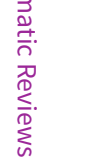 \\
\hline
\end{tabular}




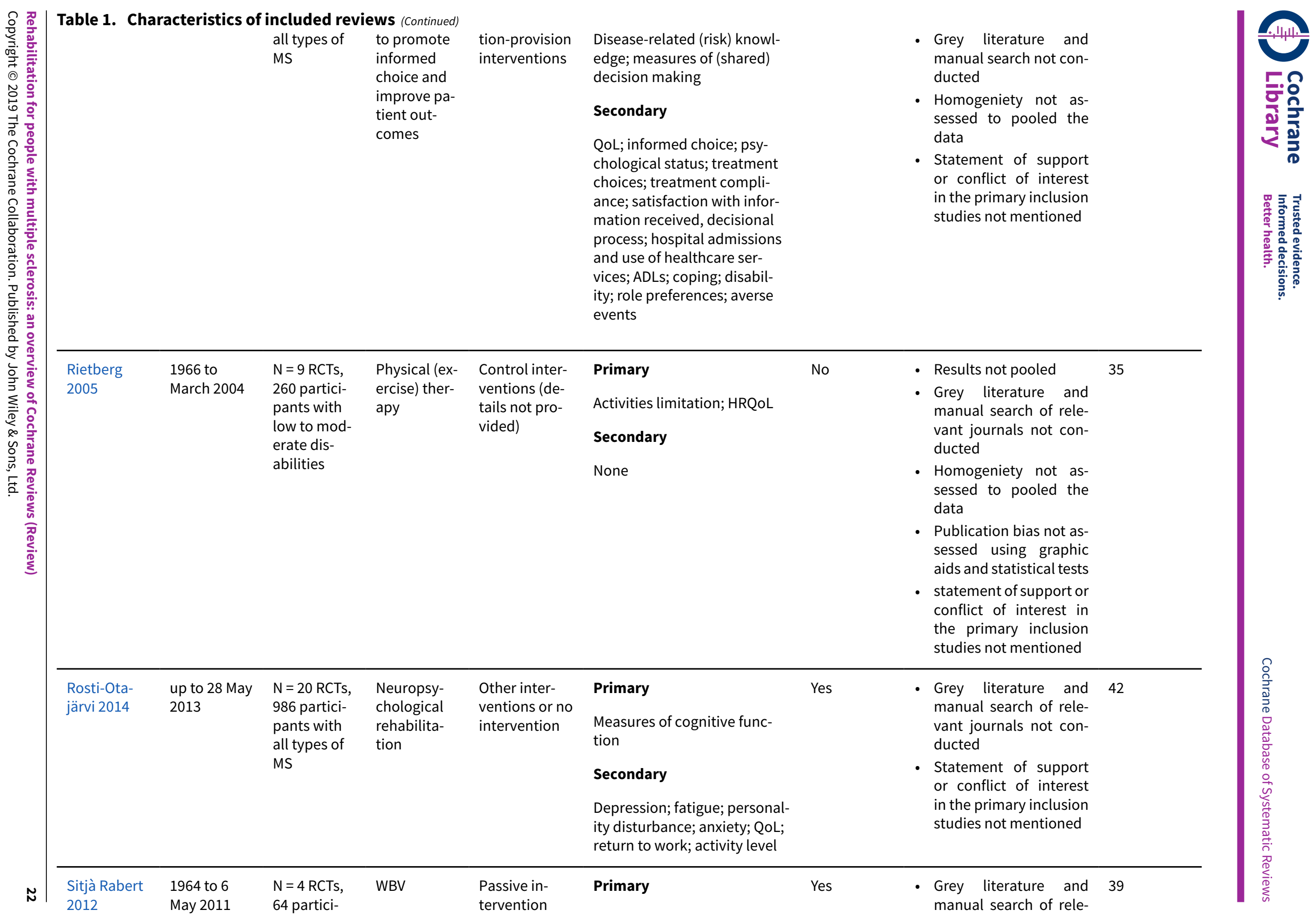




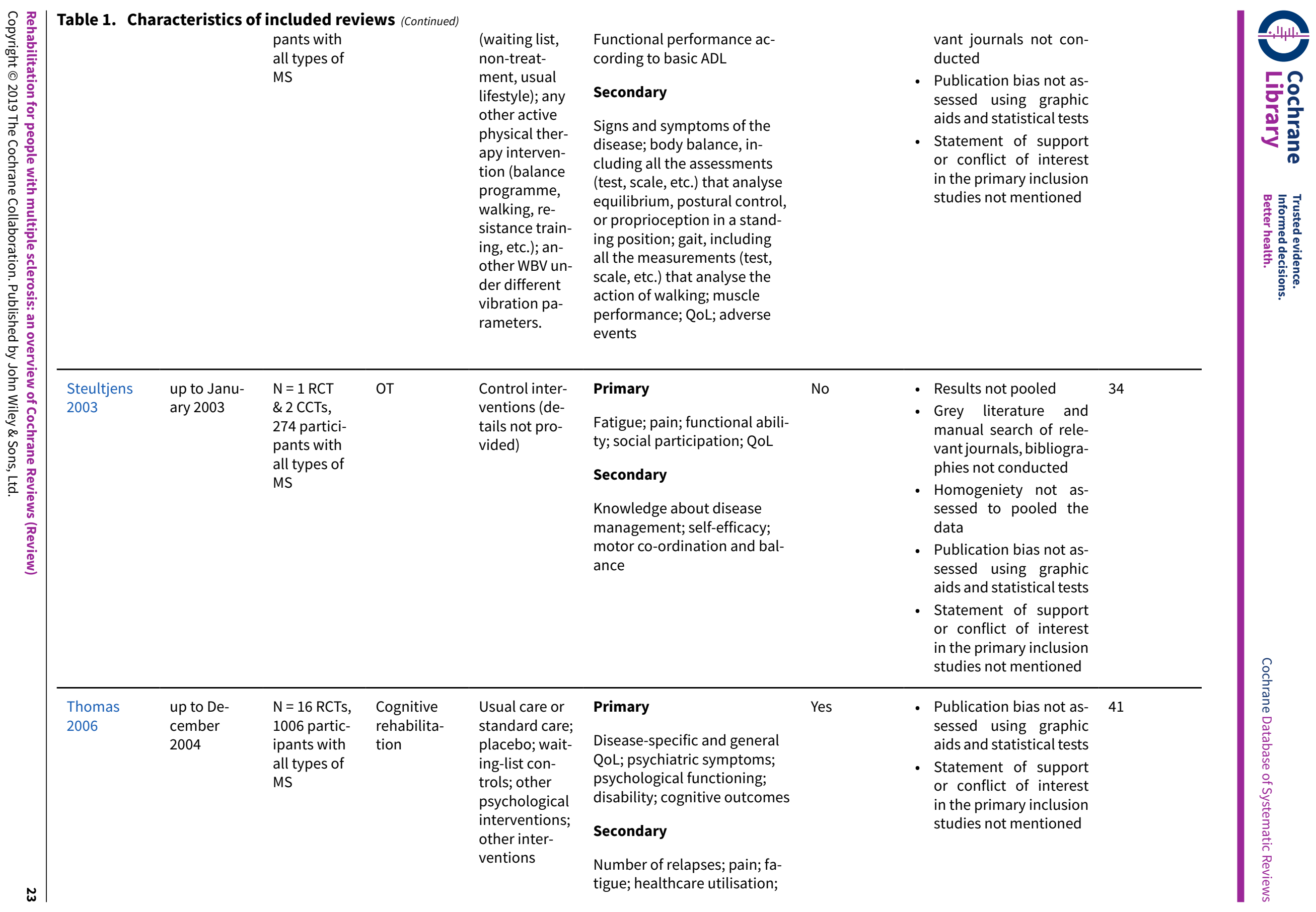




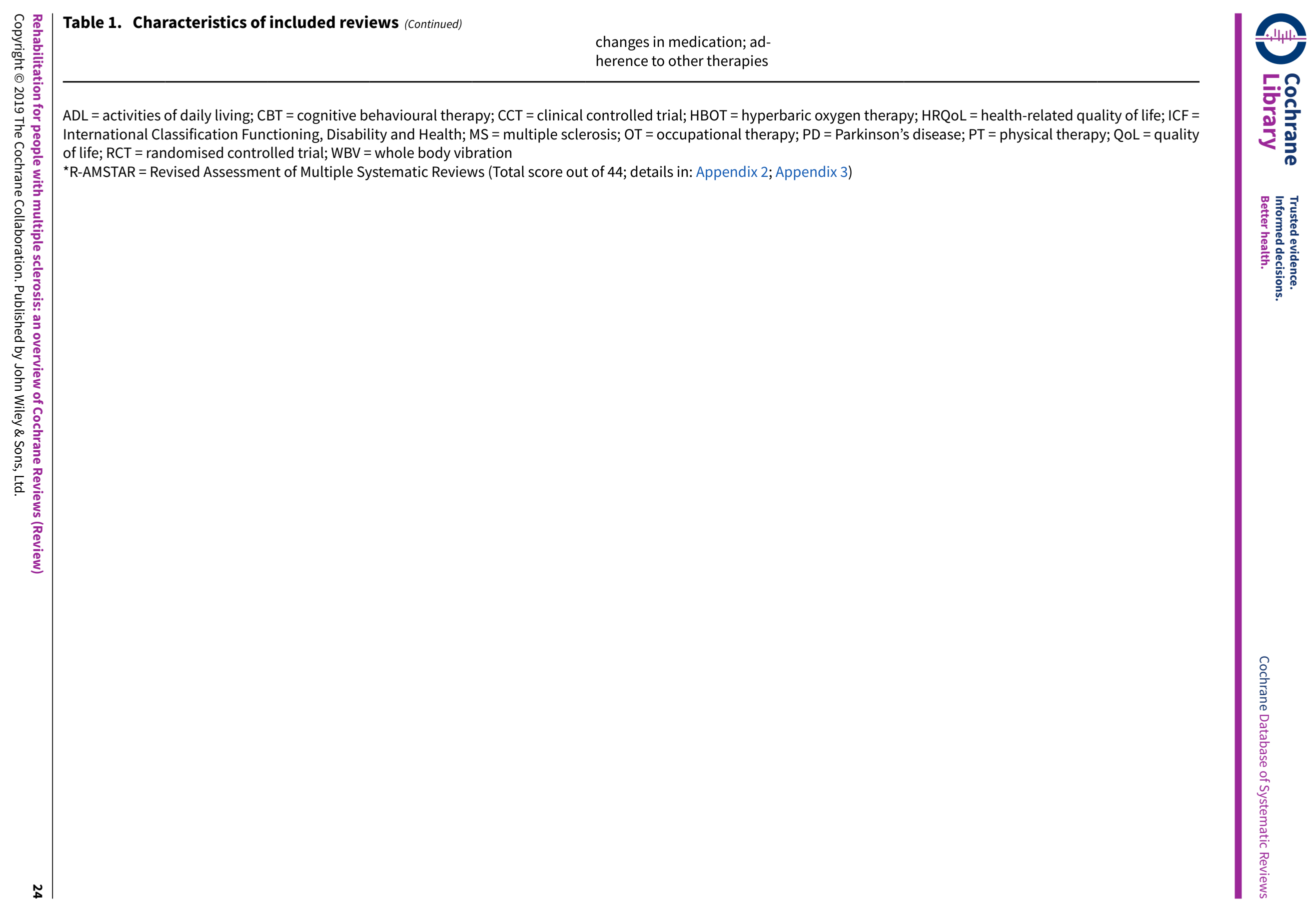


Table 2. Summary of findings from included reviews

Rehabilitation interventions for people with multiple sclerosis (pwMS)

\begin{tabular}{lllll}
\hline Outcome* $^{\star}$ & $\begin{array}{l}\text { Intervention and Com- } \\
\text { parison intervention }\end{array}$ & $\begin{array}{l}\text { Illustrative comparative risks (95\% } \\
\mathrm{Cl})\end{array}$ & $\begin{array}{l}\text { Number } \\
\text { of par- } \\
\text { ticipants } \\
\text { (studies) }\end{array}$ & $\begin{array}{l}\text { Quality } \\
\text { of the ev- } \\
\text { idence } \\
\text { (GRADE) }\end{array}$ \\
\cline { 3 - 4 } & Assumed risk & $\begin{array}{l}\text { Corresponding } \\
\text { risk }\end{array}$ & With comparator & With intervention
\end{tabular}

\begin{tabular}{ll}
\hline Function & Intervention: Multidisci- \\
(mobility, & plinary rehabilitation (MD) \\
ADLs) & - inpatient
\end{tabular}

Comparison: Lower level or different types of interventions; intervention given in different settings; lower intensity of intervention.

There was evidence that inpatient MD rehabilitation can improve functional independence, mobility and locomotion (wheelchair users only)

$\begin{array}{ll}217 \text { partic- } & \oplus \oplus \oplus \ominus \\ \text { ipants }(3 & \text { Moderate } 1 \\ \text { RCTs) } & \end{array}$

Comments Data were not pooled in this review due to design differences and use of different outcome measures

Intervention: Multidisci-
plinary rehabilitation (MD)
- inpatient or outpatient
Comparison: Lower lev-
el or different types of in-
terventions; intervention
given in different settings;
lower intensity of inter-
vention.

Intervention: Exercise

Comparison: Control interventions (details not provided)
There was evidence that an inpatient or outpatient MD rehabilitation program can improve function and bladder impairment

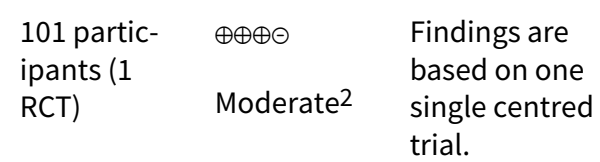

\begin{tabular}{|c|c|c|c|c|c|}
\hline $\begin{array}{l}\text { Intervention: Exercise } \\
\text { Comparison: Control in- } \\
\text { terventions (details not } \\
\text { provided) }\end{array}$ & \multicolumn{2}{|c|}{$\begin{array}{l}\text { There was evidence that exercise thera- } \\
\text { py can improve muscle power, function, } \\
\text { exercise tolerance, and mobility-related } \\
\text { activities more than no exercise. }\end{array}$} & $\begin{array}{l}260 \text { partic- } \\
\text { ipants }(9 \\
\text { RCTs) }\end{array}$ & $\begin{array}{l}\oplus \oplus \oplus \odot \\
\text { Moderate }^{1}\end{array}$ & $\begin{array}{l}\text { Data were not } \\
\text { pooled in this } \\
\text { review due to } \\
\text { variation in } \\
\text { outcome mea- } \\
\text { sures }\end{array}$ \\
\hline $\begin{array}{l}\text { Intervention: Whole-body } \\
\text { vibration } \\
\text { Comparison: Passive in- } \\
\text { tervention; any other ac- } \\
\text { tive physical therapy inter- } \\
\text { vention; another vibration }\end{array}$ & $\begin{array}{l}\text { The mean body } \\
\text { balance ranged } \\
\text { across control } \\
\text { groups from } 242 \\
\text { to } \mathbf{2 4 5} \mathbf{~ m m ~}\end{array}$ & $\begin{array}{l}\text { The mean body } \\
\text { balance in the in- } \\
\text { tervention groups } \\
\text { was } \mathbf{1 9 . 8 3} \text { higher } \\
\text { (20.99 lower to } \\
60.65 \text { higher) }\end{array}$ & $\begin{array}{l}64 \text { partic- } \\
\text { ipants ( } 4 \\
\text { RCTs) }\end{array}$ & $\begin{array}{l}\oplus \oplus \odot \odot \\
\text { Low }^{3}\end{array}$ & $\begin{array}{l}\text { Body balance } \\
\text { measured us- } \\
\text { ing the Func- } \\
\text { tional Reach } \\
\text { Test. }\end{array}$ \\
\hline
\end{tabular}
therapy under different vibration parameters

\begin{tabular}{|c|c|c|c|c|}
\hline $\begin{array}{l}\text { Intervention: Telerehabil- } \\
\text { itation programme } \\
\text { Comparison: Lower level } \\
\text { or different types of inter- } \\
\text { vention; minimal interven- } \\
\text { tion; waiting-list controls } \\
\text { or no treatment (or usual }\end{array}$ & $\begin{array}{l}\text { There was evidence that a telerehabil- } \\
\text { itation programme may improve func- } \\
\text { tional activities, such as physical activi- } \\
\text { ty, walking, balance capacity, and pos- } \\
\text { tural control for the short-term (up to } 3 \\
\text { months) }\end{array}$ & $\begin{array}{l}45 \text { partic- } \\
\text { ipants ( } 1 \\
\text { RCT) }\end{array}$ & $\begin{array}{l}\oplus \oplus \odot \odot \\
\text { Low }^{4}\end{array}$ & $\begin{array}{l}\text { Data were not } \\
\text { pooled in this } \\
\text { review due to } \\
\text { various inter- } \\
\text { ventions and } \\
\text { use of differ- } \\
\text { ent outcome } \\
\text { measures }\end{array}$ \\
\hline
\end{tabular}


Table 2. Summary of findings from included reviews (Continued)

care); interventions given

in different settings

\begin{tabular}{ll}
\hline Impar- & Intervention: Various \\
iments & non-pharmacological \\
(symp- & spasticity management in- \\
toms) & terventions
\end{tabular}

Comparison: Sham or placebo interventions; lower level or different types of intervention; minimal intervention; waiting-list controls or no treatment; interventions given in different settings

There was evidence that addition of active physiotherapy after BoNT injection may reduce spasticity up to 12 weeks: MAS score at week 2 (2.73 versus 3.22 in control), at week 4 (2.64 versus 3.33 in control), and at week 12 (2.68 versus 3.33 in control); $\mathrm{P}<0.01$ for all time points.

There was evidence that iTBS alone or in combination with exercise therapy may reduce spasticity after 2 weeks: MAS scores in the stimulated leg $(2.1 \pm 0.4$ before treatment; $1.3 \pm 0.4$ after treatment; $P<0.05)$, MSSS-88 (74.3 \pm 11.4 before treatment; $53.2 \pm 10.9$ after treatment; $\mathrm{P}<0.001), \mathrm{FSS}(39.5 \pm 4.2$ before treatment; $31.6 \pm 4.6$ after treatment; $P$ $<0.05)$.

There was evidence that rTMS may reduce spasticity (MAS score; mean change $-3.3 \pm 4.7 \mathrm{AU}$ versus $0.7 \pm 2.5 \mathrm{AU}$ in control group; $\mathrm{P}=0.003$ ).

There was evidence that pulsed electromagnetic therapy may reduce spasticity $(P<0.005)$ and fatigue $(P=0.04)$.

There was evidence that magnetic pulsing device may improve a performance scale (PS) combined rating for bladder control, cognitive function, fatigue level, mobility, spasticity, and vision (change in PS scale $-3.83 \pm 1.08$ versus $-0.17 \pm 1.07$ in control group, $\mathrm{P}<0.005$ ).

\section{Intervention: HBOT}

Comparison: Placebo or no treatment
There was evidence that HBOT may reduce mean EDSS at 12 months (group mean reduction in EDSS compared to sham $-0.85, \mathrm{P}=0.0001$ ).

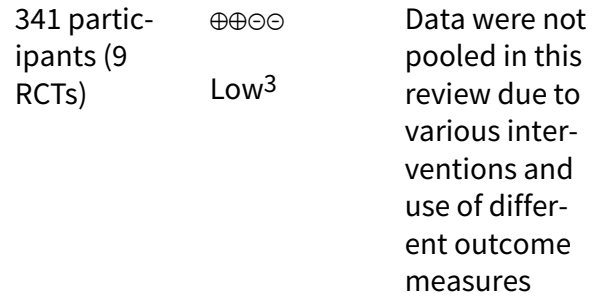

$\begin{array}{lll}\text { 504 partic- } & \oplus \oplus \odot \odot & \text { Data from } \\ \text { ipants (9 } & & \text { only 2 RCTs } \\ \text { RCTs) } & \text { Low }^{3} & \text { showed some } \\ & & \text { benefits and } \\ & \text { majority of tri- } \\ & \text { als (7 RCTs) re- } \\ & \text { ported no evi- } \\ & \text { dence }\end{array}$

2250 partic- $\oplus \oplus \oplus \ominus \quad$ There was sigipants (45 nificant hetRCTs) Moderate ${ }^{5}$ erogeneity between trials due to variability in type, duration, intensity, and use of outcome measures. 
Table 2. Summary of findings from included reviews (Continued)

Comparison: Non-exer-

cise control or another in-

tervention

\section{Intervention: Telerehabil- itation program}

Comparison: Lower level or different types of intervention; minimal intervention; waiting-list controls, no treatment, or usual care; interventions given in different settings
There was evidence that a telerehabilitation programme can reduce or improve impairments, such as fatigue in the short term (up to 3 months) and long term; and improved symptoms, such as pain and insomnia in the long term.

$\begin{array}{ll}489 \text { partic- } & \oplus \oplus \odot \odot \\ \text { ipants (4 } & \\ \text { RCTs) } & \text { Low } 1\end{array}$

Data were not pooled in this review due to various interventions and use of different outcome measures.

\section{Participa-}

tion (qual-

ity of life, psychological outcomes, vocational and social activities)

\section{Intervention: Exercise}

Comparison: Control interventions (details not provided)
There was evidence that exercise therapy can improve mood more than no exercise.

$\begin{array}{ll}260 \text { partic- } & \oplus \oplus \oplus \ominus \\ \text { ipants }(9 & \text { Moderate }^{1} \\ \text { RCTs }) & \end{array}$

Data were not pooled in this review due to variation in outcome measures

\section{Intervention: Memory re- habilitation}

Comparison: No treatment or placebo
There was evidence that memory rehabilitation may show improvement in objective assessments of memory in both immediate follow-up (SMD 0.23 , $95 \% \mathrm{Cl} 0.05$ to 0.41 ) and long-term (3 to 8 months) follow-up (SMD $0.26,95 \% \mathrm{Cl}$ 0.03 to 0.49 )

There was evidence that memory rehabilitation may improve QoL in the immediate follow-up (SMD 0.23, 95\% Cl 0.05 to 0.41 )

\begin{tabular}{|c|c|c|}
\hline $\begin{array}{l}989 \text { partic- } \\
\text { ipants (15 } \\
\text { RCTs) }\end{array}$ & $\begin{array}{l}\oplus \oplus \Theta \Theta \\
\text { Low }^{3}\end{array}$ & $\begin{array}{l}\text { The evidence } \\
\text { is limited and } \\
\text { does not ex- } \\
\text { tend to sub- } \\
\text { jective reports } \\
\text { of memory } \\
\text { functioning or } \\
\text { mood. Objec- } \\
\text { tive measures } \\
\text { used were not } \\
\text { valid, poten- } \\
\text { tially limiting } \\
\text { generalisabili- } \\
\text { ty of findings. }\end{array}$ \\
\hline
\end{tabular}

986 partic- $\oplus \oplus \ominus \ominus \quad$ Interventions and outcome RCTs) Low ${ }^{3}$ measures included in the review were heterogeneous, which limited the comparability of the studies improve attention (SMD 0.15, 95\% Cl 0.01 to $0.28 ; P=0.03$ ), immediate verbal memory (SMD 0.31, 95\% Cl 0.08 to 0.54 ; $\mathrm{P}=0.008)$, and delayed memory (SMD $0.22,95 \% \mathrm{Cl} 0.02$ to $0.42 ; \mathrm{P}=0.03$ ).

Intervention: Telerehabilitation program

Comparison: Lower level or different types of intervention; minimal intervention; waiting-list controls, no treatment, or usual
There was evidence that telerehabilitation programs might improve psychological outcomes and QoL for the long term (> 3 months)

$\begin{array}{lll}392(6 & \oplus \oplus \odot \odot & \text { Data were not } \\ \text { RCTs) } & & \text { pooled in this } \\ & \text { Lowiew due to } \\ & \text { various inter- } \\ & \text { ventions and } \\ & \text { use of differ- } \\ & \text { ent outcome } \\ & \text { measures }\end{array}$


Table 2. Summary of findings from included reviews (Continued)

care; interventions given

in different settings

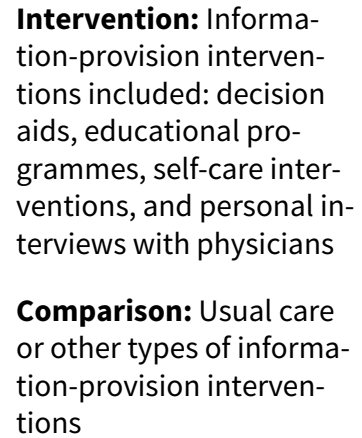

Comparison: Usual care or other types of information-provision interventions

There was evidence that information provision for patients can improve patients' disease-related knowledge.

$\begin{array}{ll}524 \text { partic- } & \oplus \oplus \oplus \odot \\ \text { ipants (4 } & \\ \text { RCTs) } & \text { Moderate }^{6}\end{array}$

Data were not pooled in this review due to the marked heterogeneity of the interventions and outcome measures.

$\mathrm{ADL}=$ activities of daily living; $\mathrm{BI}=$ Barthel Index; $\mathrm{CBT}=$ cognitive behavioural therapy; $\mathrm{CCT}$ = clinical controlled trial; $\mathrm{Cl}=$ confidence interval; EDSS = Expanded Disability Status Scale; HBOT = hyperbaric oxygen therapy; FSS = Fatigue Severity Scale; HRQoL = health-related quality of life; iTBS = intermittent theta burst stimulation; MS = multiple sclerosis; MSQOL-54 = Multiple Sclerosis Quality of Life; MSSS-88 = Multiple Sclerosis Spasticity Scale; OT = occupational therapy; pwMS = persons with multiple sclerosis; PT = physical therapy; PUFAs = polyunsaturated fatty acids; $\mathrm{QoL}$ = quality of life; $\mathrm{RCT}$ = randomised controlled trial; $r \mathrm{TMS}$ = repetitive transcranial magnetic stimulation; SMD = standardised mean difference; TENS = transcutaneous electrical nerve stimulation; VAS = visual analogue scale

${ }^{*}$ Outcomes categorised according to the International Classification Functioning, Disability and Health (ICF, WHO 2001).

${ }^{\star \star}$ GRADE Working Group grades of evidence

High quality: Further research is very unlikely to change our confidence in the estimate of effect.

Moderate quality: Further research is likely to have an important impact on our confidence in the estimate of effect, and may change the estimate.

Low quality: Further research is very likely to have an important impact on our confidence in the estimate of effect, and is likely to change the estimate.

Very low quality: We are very uncertain about the estimate.

1Downgraded by one level for imprecision and inconsistency of findings and use of different outcome measures.

2 Downgraded by one level due to high risk for imprecision (one single site study).

${ }^{3}$ Downgraded by two levels for imprecision and inconsistency of findings, due to a number of methodological flaws (high risk of bias in randomisation sequence generation, allocation concealment and blinding) and use of different outcome measures.

${ }^{4}$ Downgraded two levels because the singular study was considered at high risk of bias (unclear risk of bias in randomisation, sequence generation, allocation concealment and blinding of outcome assessors).

5Downgraded by one level for imprecision and inconsistency of findings and majority of trials had small sample size and assessed fatigue as a secondary measure.

${ }^{6}$ Downgraded by one level for imprecision and inconsistency of findings, use of different outcome measures and high risk of bias.

\section{A P PE N DICES}

\section{Appendix 1. Key words for the search strategy}

\section{Theme 1. Multiple sclerosis}

Multiple Sclerosis, Demyelinating Diseases, Transverse myelitis, Optic Neuritis, Acute disseminated encephalomyelitis

\section{Theme 2. Rehabilitation interventions}

Rehabilitation, Ambulatory Care, Physical Therapy Modalities, physiotherapy, Exercise therapy, Cognitive therapy, psychotherapy, Behavior/behaviour therapy, Social work, Counselling, Occupational Therapy, Dietetics/Nutrition, Orthotics/brace/orthoses, Acupuncture Patient Care Team, multidisciplinary/ integrated team, cold treatment/cooling, assistive technology device, hydro/pool therapy, Electromagnetic therapy, nerve stimulation, vibration therapy, social participation/support, vocational rehabilitation

\section{MeSH check words}

Systematic review/meta-analysis, Review, Adult; Humans 


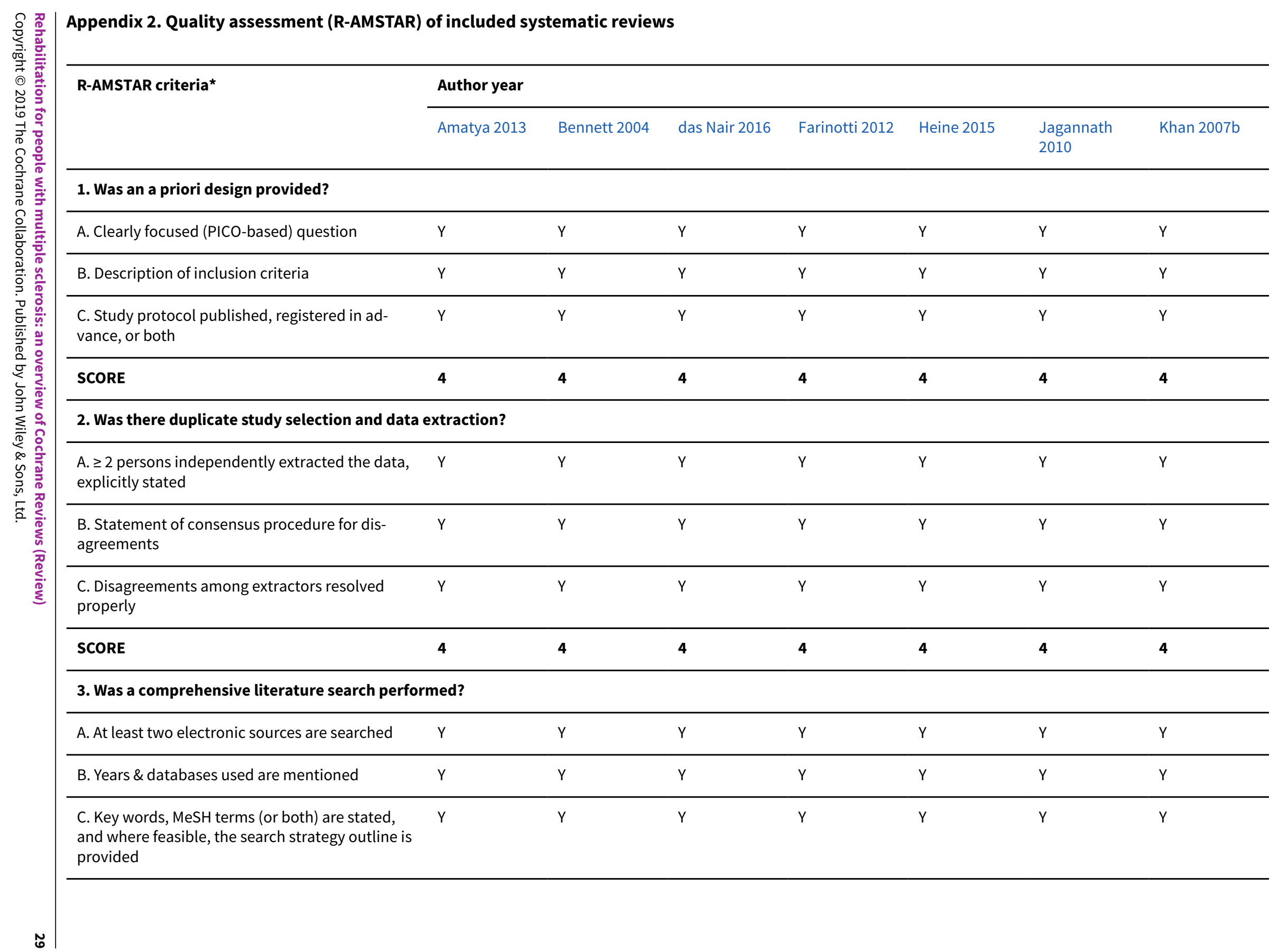




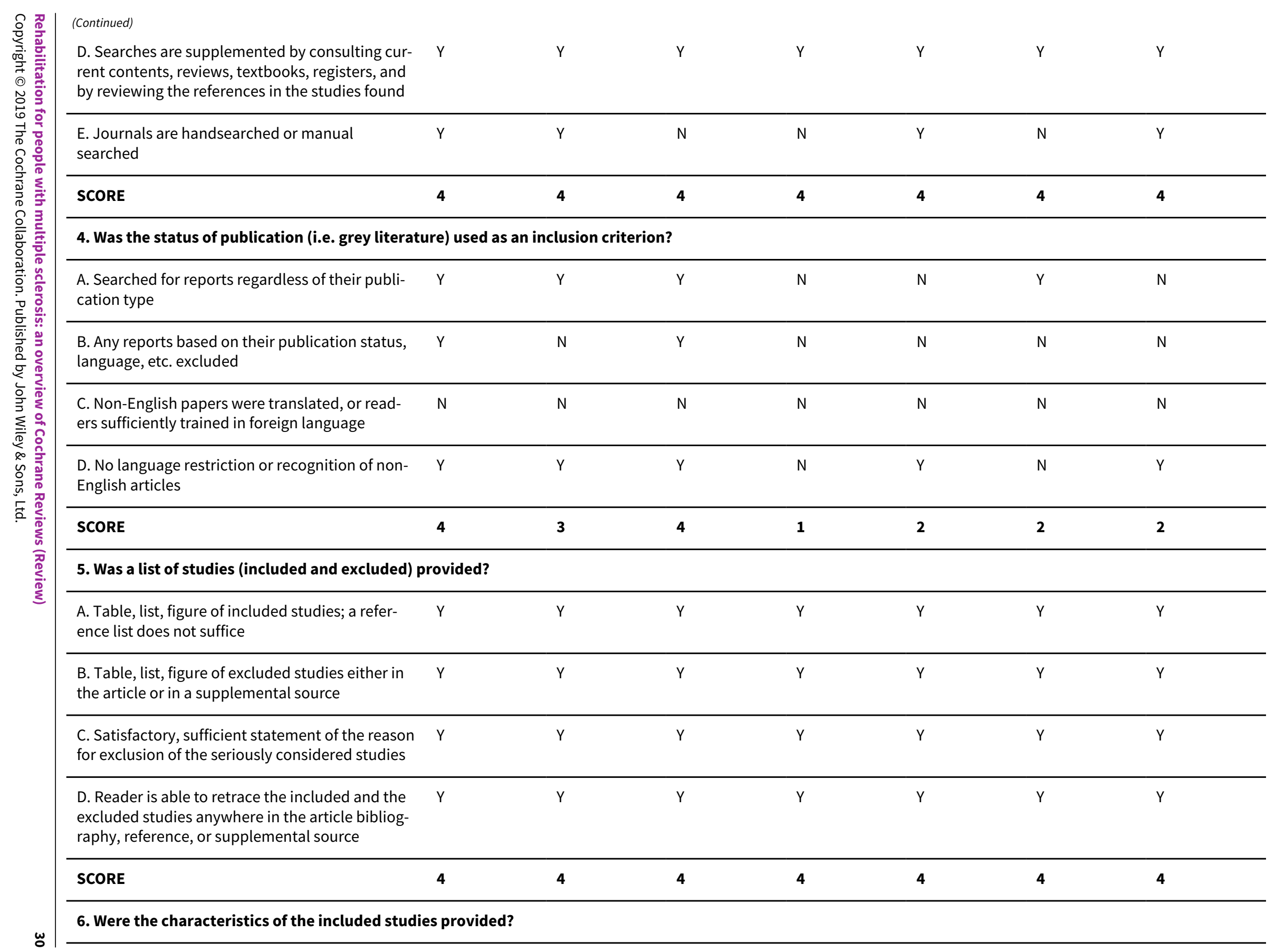




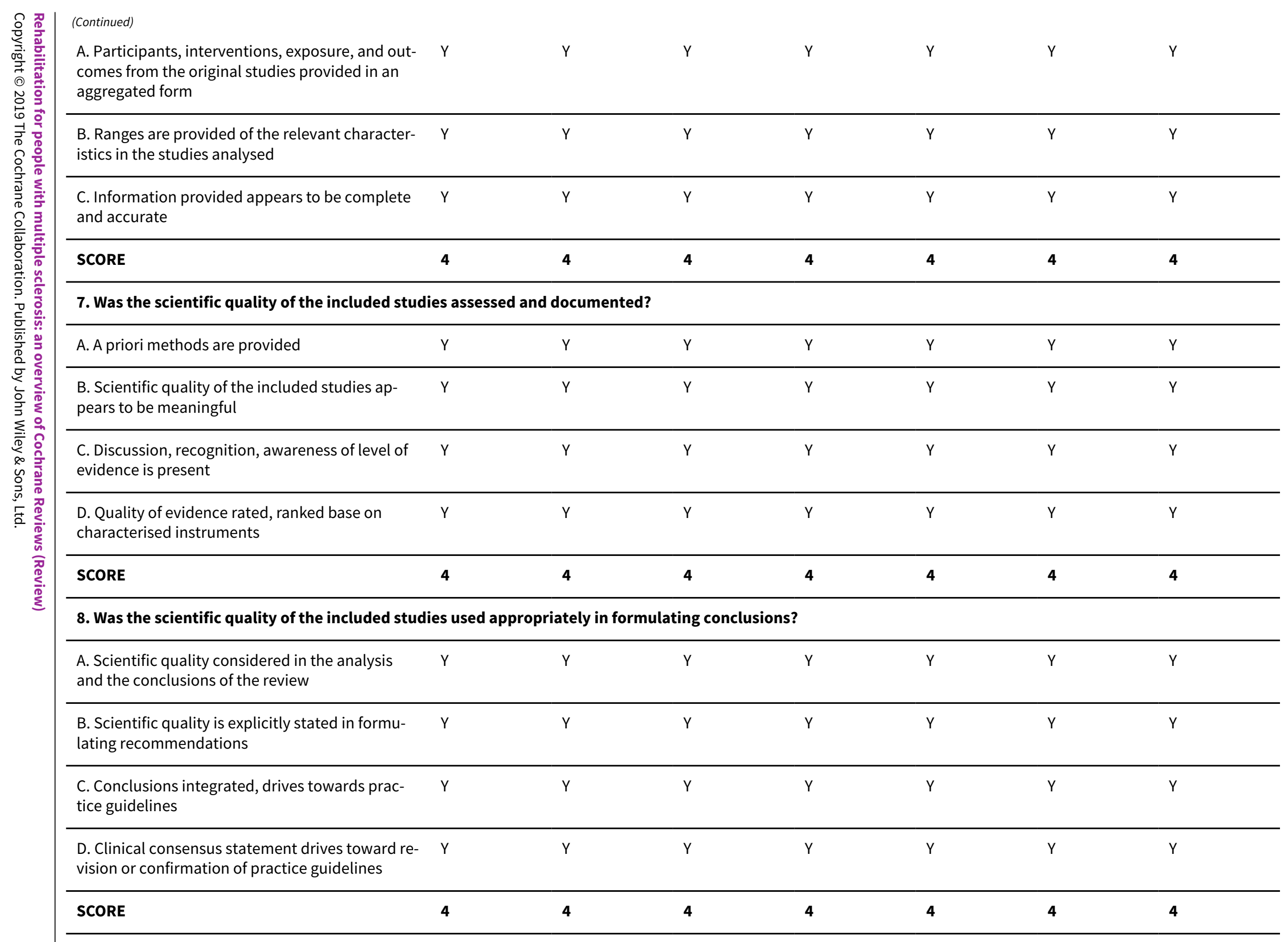




\begin{tabular}{|c|c|c|c|c|c|c|c|c|}
\hline \multirow{3}{*}{\multicolumn{2}{|c|}{ 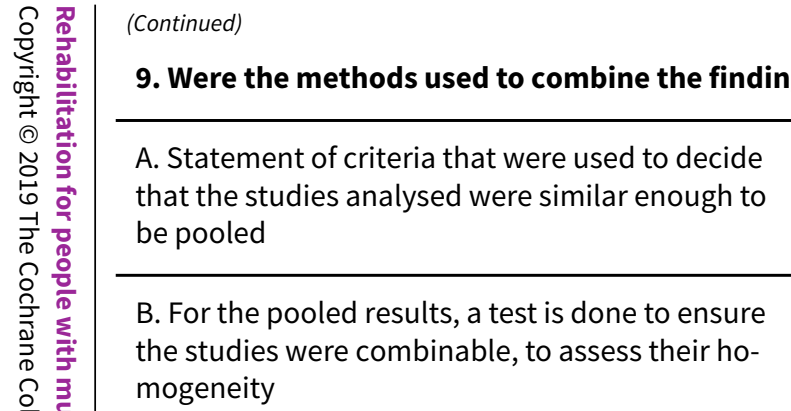 }} & \multicolumn{3}{|c|}{ gs of studies appropriate? } & \multirow[b]{2}{*}{$Y$} & \multirow[b]{2}{*}{$\mathrm{Y}$} & \multirow[b]{2}{*}{$Y$} & \multirow[b]{2}{*}{$Y$} \\
\hline & & $Y$ & $Y$ & $Y$ & & & & \\
\hline & & $\mathrm{N}$ & $Y$ & $Y$ & $Y$ & $Y$ & $Y$ & $Y$ \\
\hline 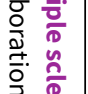 & $\begin{array}{l}\text { C. A recognition of heterogeneity or lack of there- } \\
\text { of is present }\end{array}$ & $Y$ & $Y$ & $Y$ & $Y$ & $Y$ & $Y$ & $Y$ \\
\hline 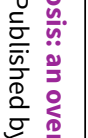 & $\begin{array}{l}\text { D. If heterogeneity exists, a random-effects mod- } \\
\text { el is used, the rationale of combining is taken in- } \\
\text { to consideration, or both }\end{array}$ & $Y$ & $Y$ & $Y$ & $Y$ & $Y$ & $Y$ & $Y$ \\
\hline 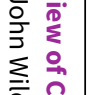 & $\begin{array}{l}\text { E. If homogeneity exists, a rationale or a statisti- } \\
\text { cal test is stated }\end{array}$ & $Y$ & $Y$ & $Y$ & $Y$ & $Y$ & $Y$ & $Y$ \\
\hline 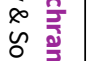 & SCORE & 4 & 4 & 4 & 4 & 4 & 4 & 4 \\
\hline$\frac{1}{2}$ & \multicolumn{8}{|l|}{ 10. Was the likelihood of publication bias assessed? } \\
\hline 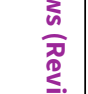 & $\begin{array}{l}\text { A. Recognition of publication bias or file drawer } \\
\text { effect }\end{array}$ & Y & Y & Y & $\mathrm{Y}$ & $\mathrm{Y}$ & $\mathrm{Y}$ & $\mathrm{Y}$ \\
\hline & B. Graphical aids (e.g. funnel plot) & $\mathrm{N}$ & $\mathrm{N}$ & $\mathrm{N}$ & $\mathrm{N}$ & $\mathrm{N}$ & $\mathrm{N}$ & $\mathrm{N}$ \\
\hline & C. Statistical tests (e.g. Egger regression test) & $\mathrm{N}$ & $\mathrm{Y}$ & Y & $\mathrm{Y}$ & $\mathrm{Y}$ & $\mathrm{Y}$ & $\mathrm{Y}$ \\
\hline & SCORE & 2 & 3 & 3 & 3 & 3 & 3 & 3 \\
\hline & \multicolumn{8}{|l|}{ 11. Was the conflict of interest included? } \\
\hline & A. Statement of sources of support & Y & $\mathrm{Y}$ & Y & $\mathrm{Y}$ & $\mathrm{Y}$ & $\mathrm{Y}$ & $\mathrm{Y}$ \\
\hline & B. No conflict of interest & Y & $\mathrm{Y}$ & Y & $\mathrm{Y}$ & $\mathrm{Y}$ & $\mathrm{Y}$ & $\mathrm{Y}$ \\
\hline & $\begin{array}{l}\text { C. An awareness, statement of support or conflict } \\
\text { of interest in the primary inclusion studies }\end{array}$ & $\mathrm{N}$ & $\mathrm{N}$ & $\mathrm{N}$ & $\mathrm{N}$ & $\mathrm{N}$ & $\mathrm{N}$ & $\mathrm{N}$ \\
\hline & SCORE & 3 & 3 & 3 & 3 & 3 & 3 & 3 \\
\hline
\end{tabular}

. If heterogeneity exists, a random-effects mod-

to consideration, or both

10. Was the likelihood of publication bias assessed?

A. Recognition of publication bias or file drawer

11. Was the conflict of interest included? 


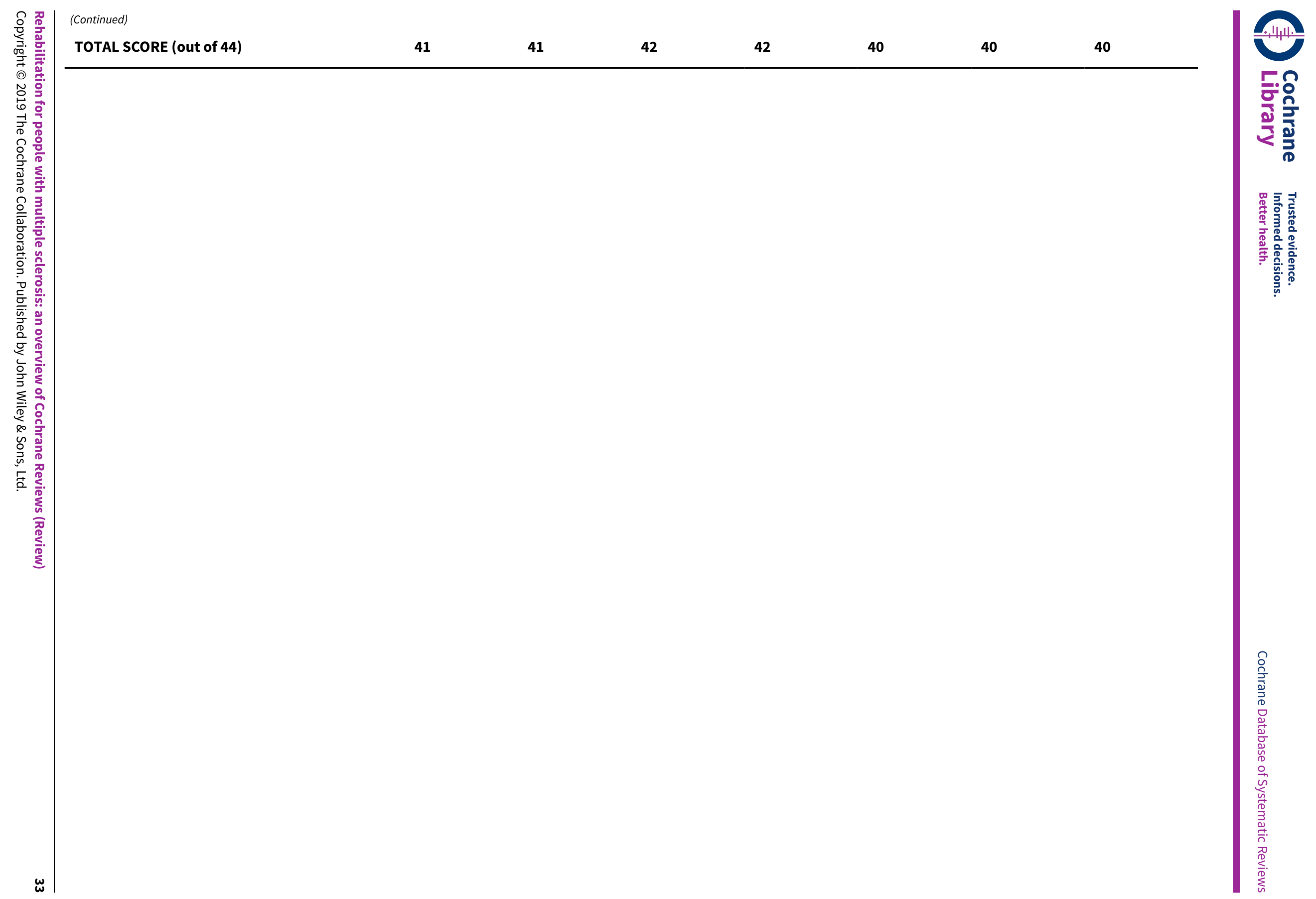




\section{Footnotes}

${ }^{*}$ Revised-Assessment of Multiple Systematic Reviews (R-AMSTAR) criteria

$\mathrm{Y}=\mathrm{Yes}$, criteria met (1 point), $\mathrm{N}=$ No, criteria not met (0 points) 


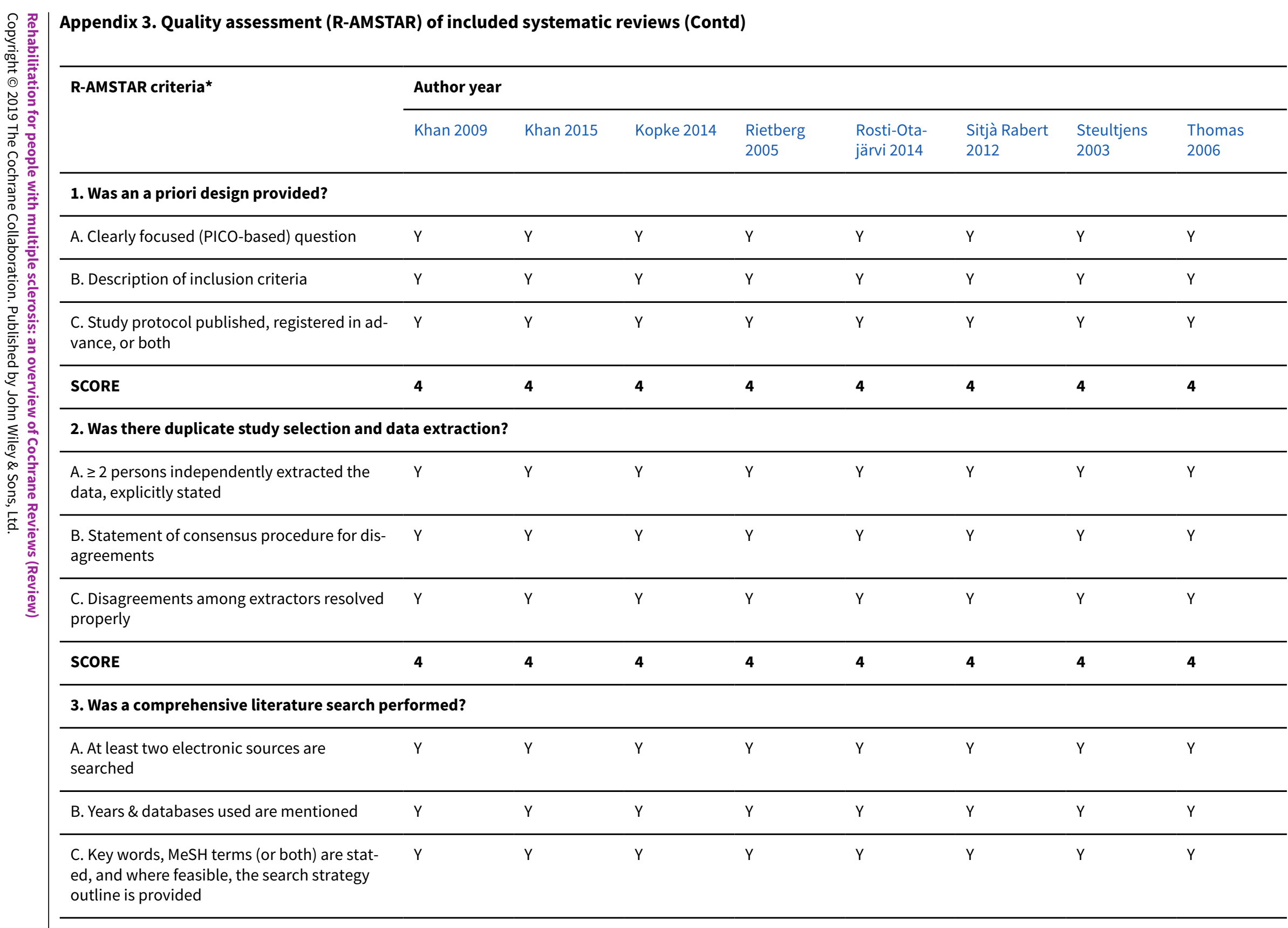




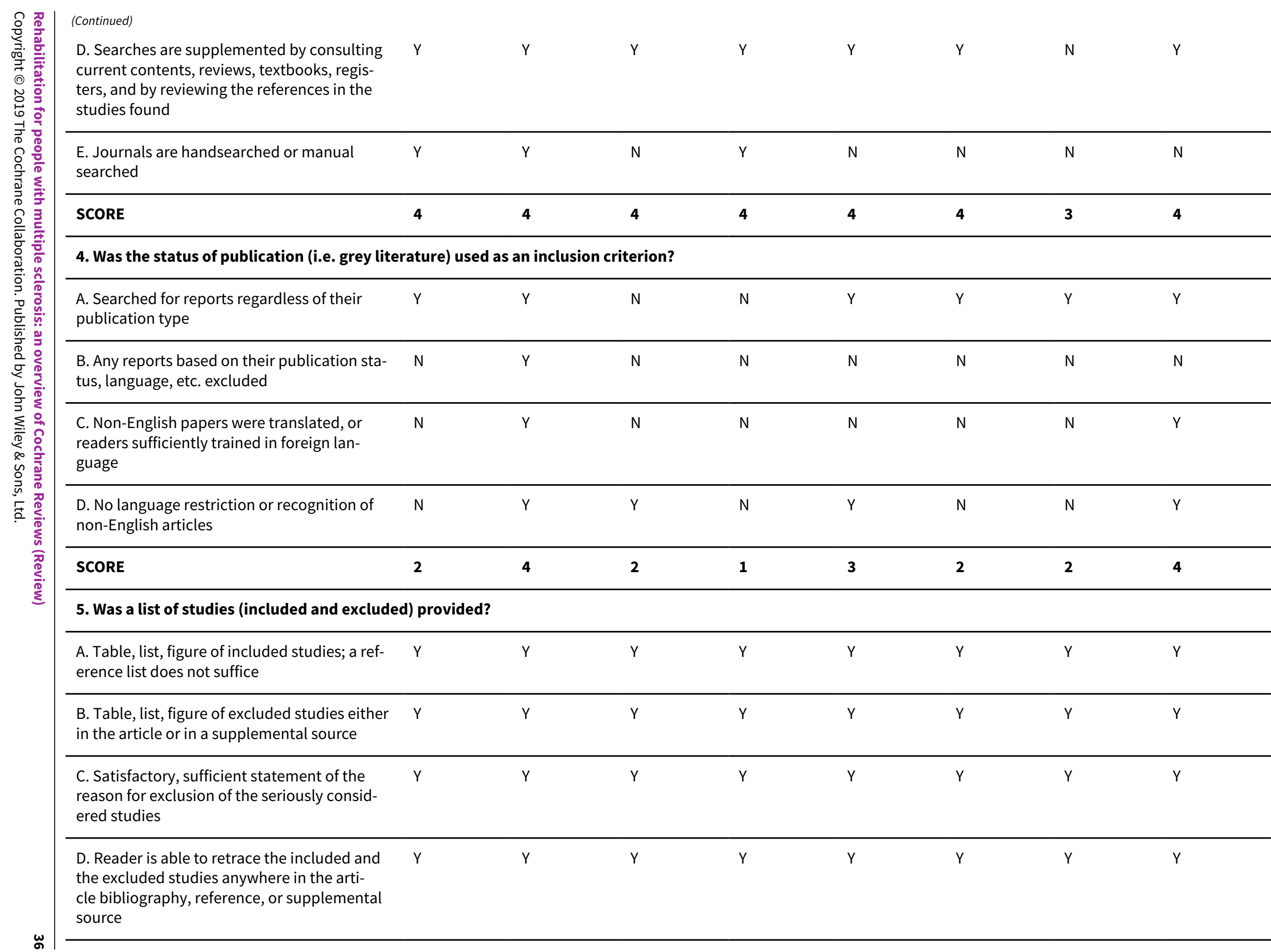




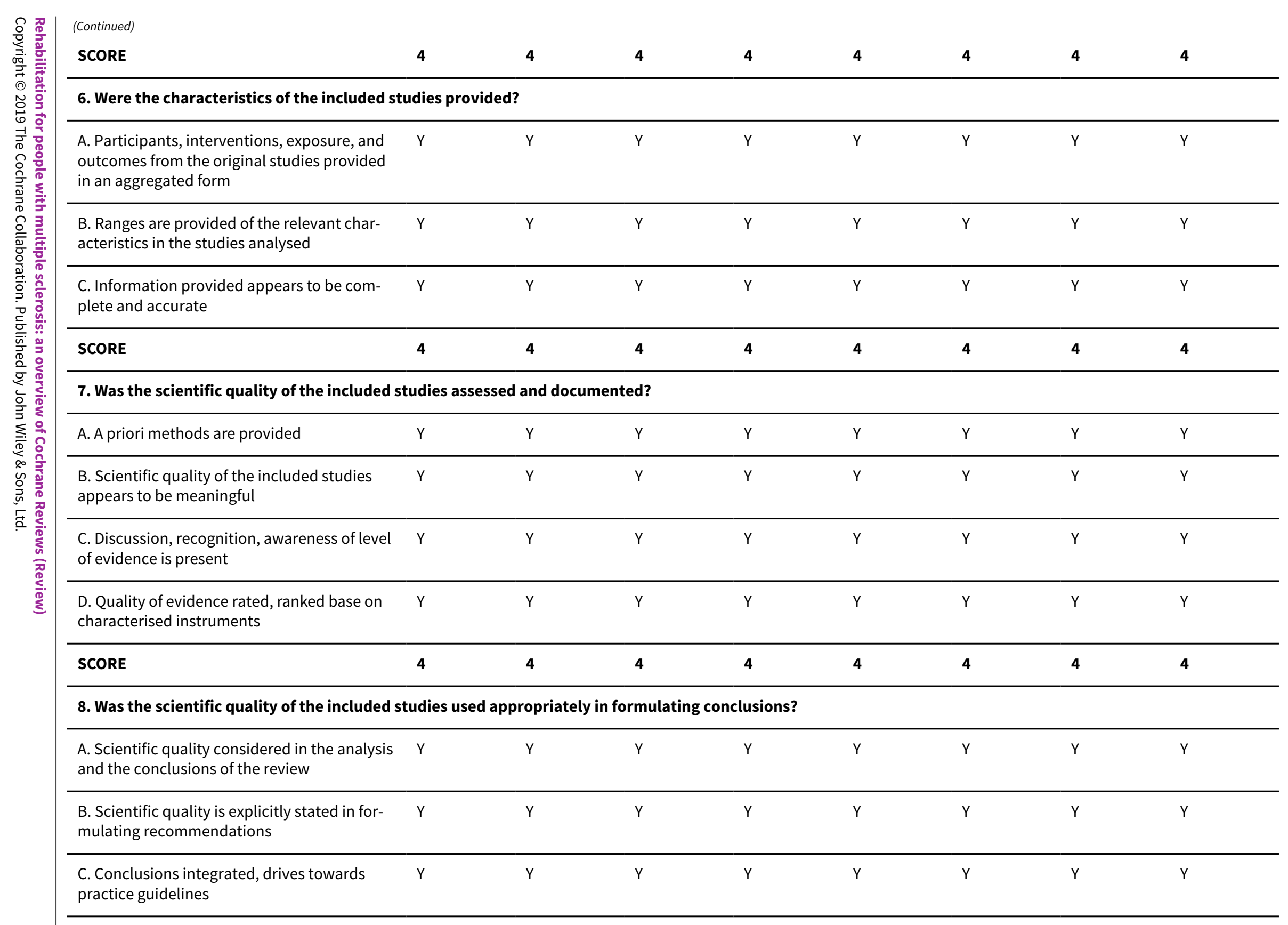


D. Clinical consensus statement drives toward revision or confirmation of practice guidelines

4

4

4

4

4

4

$4 \quad 4$

9. Were the methods used to combine the findings of studies appropriate?

A. Statement of criteria that were used to de- $Y \quad Y$

cide that the studies analysed were similar

enough to be pooled

\begin{tabular}{lllllll}
\hline $\begin{array}{l}\text { B. For the pooled results, a test is done to en- } \\
\text { sure the studies were combinable, to assess } \\
\text { their homogeneity }\end{array}$ & $\mathrm{Y}$ & $\mathrm{N}$ & $\mathrm{Y}$ & $\mathrm{Y}$ \\
\hline $\begin{array}{l}\text { C. A recognition of heterogeneity or lack of } \\
\text { thereof is present }\end{array}$ & $\mathrm{Y}$ & $\mathrm{Y}$ & $\mathrm{Y}$ & $\mathrm{N}$ & $\mathrm{Y}$ & $\mathrm{N}$ \\
\hline $\begin{array}{l}\text { D. If heterogeneity exists, a random-effects } \\
\text { model is used, the rationale of combining is } \\
\text { taken into consideration, or both }\end{array}$ & $\mathrm{Y}$ & $\mathrm{Y}$ & $\mathrm{N}$ & $\mathrm{N}$ & $\mathrm{Y}$ & $\mathrm{N}$ \\
\hline $\begin{array}{l}\text { E. If homogeneity exists, a rationale or a sta- } \\
\text { tistical test is stated }\end{array}$ & $\mathrm{Y}$ & $\mathrm{Y}$ & $\mathrm{N}$ & $\mathrm{N}$ & $\mathrm{Y}$ & $\mathrm{Y}$ \\
\hline SCORE & $\mathbf{4}$ & $\mathbf{4}$ & $\mathbf{2}$ & $\mathrm{1}$ & $\mathrm{N}$ \\
\hline
\end{tabular}

10. Was the likelihood of publication bias assessed?

\begin{tabular}{lllllll}
\hline $\begin{array}{l}\text { A. Recognition of publication bias or file } \\
\text { drawer effect }\end{array}$ & $\mathrm{Y}$ & $\mathrm{Y}$ & $\mathrm{Y}$ & $\mathrm{Y}$ & $\mathrm{Y}$ & $\mathrm{N}$ \\
\hline B. Graphical aids (e.g. funnel plot) & $\mathrm{N}$ & $\mathrm{N}$ & $\mathrm{N}$ & $\mathrm{N}$ & $\mathrm{Y}$ & $\mathrm{N}$ \\
\hline C. Statistical tests (e.g. Egger regression test) & $\mathrm{Y}$ & $\mathrm{Y}$ & $\mathrm{Y}$ & $\mathrm{N}$ & $\mathrm{N}$ & $\mathrm{N}$ \\
\hline SCORE & $\mathbf{3}$ & $\mathbf{3}$ & $\mathbf{3}$ & $\mathbf{2}$ & $\mathbf{4}$ & $\mathbf{2}$ \\
\hline
\end{tabular}

\section{Was the conflict of interest included?}

A. Statement of sources of support

Y

Y

Y

Y

Y

Y

Y

Y 


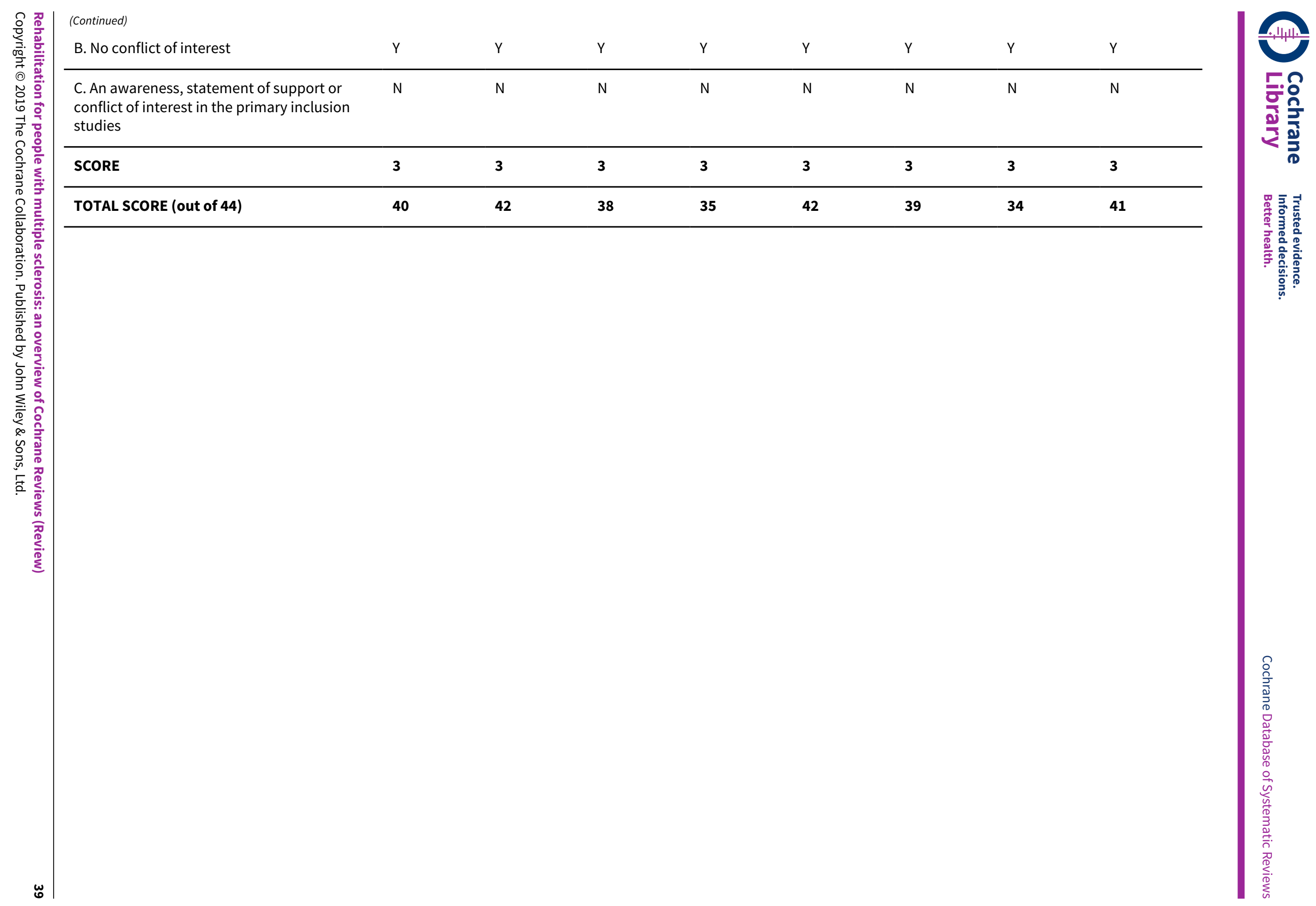




\section{Footnotes}

${ }^{*}$ Revised-Assessment of Multiple Systematic Reviews (R-AMSTAR) criteria

$\mathrm{Y}=$ Yes, criteria met (1 point), $\mathrm{N}=$ No, criteria not met (0 points)

CONTRIBUTIONS OF AUTHORS

\begin{tabular}{ll}
\hline Task & Review author undertaking \\
\hline Protocol stage & Bhasker Amatya, Fary Khan \\
\hline Draft protocol & All review authors \\
\hline Review of the protocol & \\
\hline Review stage & Bhasker Amatya, Fary Khan \\
\hline Study selection and data extraction & Bhasker Amatya, Fary Khan \\
\hline Critical appraisals and analyses & All review authors \\
\hline Interpretation of findings & All review authors \\
\hline Review the content & Bhasker Amatya \\
\hline Draft final review & \\
\hline Update stage & All authors \\
\hline Update the review & \\
\hline
\end{tabular}

\section{DECLARATIONS OF INTEREST}

The review authors are clinicians in the field of Physical and Medical Rehabilitation who wish to provide the best possible service to their patients.

Bhasker Amatya: none

Fary Khan: none

Mary Galea: none

The authors acknowledge that four included reviews were conducted by the present authors' team (Amatya 2013; Khan 2007b; Khan 2009; Khan 2015), and one author (FK) was involved in another review (Kopke 2014).

\section{SOURCES OF SUPPORT}

\section{Internal sources}

- Department of Rehabilitation Medicine, Royal Melbourne Hospital, Australia.

\section{External sources}

- None, Other.

\section{INDEX TERMS}

\section{Medical Subject Headings (MeSH)}

*Physical Therapy Modalities; *Systematic Reviews as Topic; Controlled Clinical Trials as Topic; Multiple Sclerosis [ ${ }^{\star}$ rehabilitation]; Quality of Life; Randomized Controlled Trials as Topic 


\section{MeSH check words}

Humans 